\title{
Cortical-layer specific effects of PACAP and tPA on interneuron migration during post-natal development of the cerebellum
}

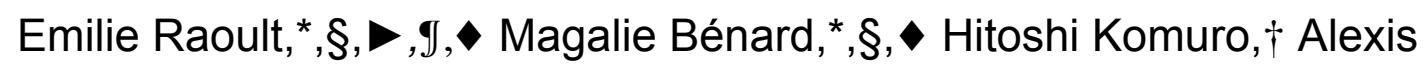
Lebon, ${ }^{\star}, \S$, , I Denis Vivien,\# Alain Fournier,J, $\$$ Hubert Vaudry, ${ }^{*}, \S, \$$,I David Vaudry, ${ }^{*}, \S$, ,I and Ludovic Galas ${ }^{*}, \S$

*Inserm, PRIMACEN, Cell Imaging Platform of Normandy, Mont-Saint-Aignan, France

$\S$ University of Rouen, Institute for Research and Innovation in Biomedicine (IRIB),

Rouen, France

-Inserm, U982, DC2N, Mont-Saint-Aignan, France

IInternational Associated laboratory Samuel de Champlain, Inserm-INRS, France-

Canada

${ }^{\dagger}$ Department of Neuroscience/NC30, Lerner Research Institute, The Cleveland Clinic

Foundation, Cleveland, $\mathrm{OH}, \mathrm{USA}$

Inserm, U919, SP2U, Cyceron, Caen, France

$¥$ Institut National de la Recherche Scientifique — Institut Armand-Frappier, Université du Québec, Laval, Canada

- The first two authors contributed equally to this work.

36 pages of text and 8 figures 
Raoult et al, page 2

Address correspondence and reprint requests to Ludovic Galas, Inserm, PRIMACEN, Cell Imaging Platform of Normandy, Institute for Research and Innovation in Biomedicine (IRIB), University of Rouen, 76821 Mont-Saint-Aignan, E-mail: ludovic.galas@univ-rouen.fr

Abbreviation used: AOBS, acousto-optical beam splitter; B/SC, basket/stellate cells; BSA, bovine serum albumin; CTG, cell tracker green; GN, cerebellar granule neurons; DAPI, 4'6-diamidino-2-phenylindole; DMEM, Dubelcco's modified eagle medium; EGL, external granular layer; EM, extracellular matrix; HBSS, Hank's buffered salt solution; IGL; internal granular layer; ML, molecular layer; PACAP, pituitary adenylate cyclaseactivating polypeptide; PAI-1, plasminogen activator inhibitor; PBS, phosphate-buffered saline; PCL, Purkinje cell layer; sst, somatostatin; tPA, tissue-type plasminogen activator; WM, white matter. 
Raoult et al, page 3

\section{Abstract}

During early postnatal development of the cerebellum, granule neurons (GN) execute a centripetal migration toward the internal granular layer (IGL) while basket and stellate cells $(B / S C)$ migrate centrifugally to reach their final position in the molecular layer $(M L)$. We have previously shown that pituitary adenylate cyclase-activating polypeptide (PACAP) stimulates in vitro the expression and release of the serine protease tissuetype plasminogen activator (TPA) from GN but the coordinated role of PACAP and IPA during interneuron migration has not yet been investigated. Here, we show that endogenous PACAP is responsible for the transient arrest phase of GN at the level of the Purkinje cell layer (PCL) but has no effect on B/SC. tPA is devoid of direct effect on GN motility in vitro, although it is widely distributed along interneuron migratory routes in the ML, PCL and IGL. Interestingly, plasminogen activator inhibitor 1 (PAI-1) reduces the migration speed of $\mathrm{GN}$ in the $\mathrm{ML}$ and $\mathrm{PCL}$, and that of $\mathrm{B} / \mathrm{SC}$ in the ML. Taken together, these results reveal for the first time that tPA facilitates the migration of both $\mathrm{GN}$ and fast $\mathrm{B} / \mathrm{SC}$ at the level of their intersection in the $\mathrm{ML}$ through extracellular matrix (EM) degradation.

Keywords: PACAP, tPA, granule neurons, basket and stellate cells, interneuron migration, cerebellum 
Raoult et al, page 4

During brain development, the migration of immature neurons from germinative zones to their final destination is essential for the establishment of proper neuronal circuits (Rakic 1990; Hatten 1999; Komuro and Yacubova 2003, Evsyukova et al. 2013). Impairment of this process results in either cell death or misplacement of the neurons, leading to deficiency of diverse brain functions (Rakic 1988; Flint and Kriegstein 1997; Gressens 2006). In the developing cerebellum, immature granule neurons (GN; excitatory interneurons) and basket/stellate cells (B/SC; inhibitory interneurons) originate from two separate germinative zones, and exhibit distinct modes of migration over the same developmental period i.e. the first 3 postnatal weeks (Komuro and Yacubova 2003; Consalez and Hawkes 2013). Thus, upon completion of their final mitosis, GN migrate tangentially within the external granular layer (EGL) and then change direction to migrate radially along the processes of Bergmann glial cells through the molecular layer (ML) (Komuro et al. 1998, 2001). When entering the Purkinje cell layer (PCL), GN detach from glial cells and slow down (Komuro and Rakic 1998). Two hours later, GN resume their migration and cross the border between the PCL and the internal granular layer (IGL). Within the IGL, GN migrate radially until reaching their final position at the bottom of the IGL (Komuro and Rakic 1998). In contrast to GN, less is known for B/SC migration but they exhibit a centrifugal move during early post-natal development from the deep white matter to the ML (Zhang and Goldman 1996; Milosevic and Goldman 2004) where they complete their migration in four phases (Cameron et al. 2009a). 
Raoult et al, page 5

Pituitary adenylate cyclase-activating polypeptide (PACAP) is a 38-amino acid neuropeptide whose primary structure has been remarkably well conserved during evolution (Vaudry et al. 2000). PACAP belongs to a family of structurally related peptides, comprising secretin, glucagon, vasoactive intestinal polypeptide, peptide histidine-isoleucine, growth hormone-releasing hormone and helodermin (Vaudry et al. 2009). In the postnatal cerebellum of rodents, PACAP is expressed sporadically at the bottom of the ML, intensively in the PCL, and throughout the IGL (Nielsen et al. 1998; Hannibal 2002; Cameron et al. 2007). In vitro and ex vivo studies have shown that PACAP exerts an inhibitory effect on GN migration (Falluel-Morel et al. 2005; Cameron et al. 2007). In particular, endogenous PACAP is responsible for the transient arrest phase in the PCL that lasts for approximately $2 \mathrm{~h}$ (Cameron et al. 2007). Recently, PACAP has been shown to stimulate in vitro the expression and release of tissueplasminogen activator (tPA) which contributes to the neuroprotective effect of PACAP on GN (Raoult et al. 2011). tPA is an extracellular serine protease that converts the proenzyme plasminogen into the active protease plasmin, which in turn degrades extracellular matrix (EM) components such as cell adhesion molecules or laminin (Garcia-Rocha et al. 1994; Yepes and Lawrence 2004). tPA-induced proteolysis and endogenous protease inhibitors, including plasminogen activator inhibitor-1 (PAI-1), are known to play key roles in neuritogenesis, neuronal plasticity and death (Melchor and Strickland 2005). Interestingly, during the development of postnatal cerebellum, tPA is detected in leading processes of GN (Krystosek and Seeds 1981a,b; Seeds et al. 1997) and facilitates GN migration (Seeds et al. 1999). The developing cerebellum of tPA- 
deficient mice exhibits an increased number of $G N$ in transit within the ML as a result of a decrease of neuronal migration speed (Seeds et al. 1999). As a matter of fact, plasminogen mRNA is widely expressed in the cerebellar EGL, ML and IGL of newborn mice (Basham and Seeds 2001).

Centripetal GN and centrifugal B/SC migration may involve different mechanisms, such as chimiotactism or EM degradation, to guide the cells. Several molecules which affect the velocity of GN have already been identified (Cameron et al. 2009), but the exact mechanisms involved in the control of cell migration in each cortical layer are still largely unknown. Furthermore, no factor regulating B/SC movement during brain development has been identified so far (Cameron et al. 2009). The aim of the present study was thus to determine a possible role of PACAP, tPA and PACAP-induced tPA release in the centripetal $\mathrm{GN}$ and centrifugal $\mathrm{B} / \mathrm{SC}$ migrations in the rat cerebellar cortical layers. 
Raoult et al, page 7

\section{Materials and methods}

\section{Reagents and drugs}

Poly-D-Lysine, poly-L-lysine, laminin and antibiotic-antimycotic solution were purchased from Sigma-Aldrich (Saint-Quentin Fallavier, France). Dubelcco's modified eagle medium (DMEM), Ham's F12, Hank's buffered salt solution (HBSS), bovine serum albumin (BSA) and N2 supplement were from Fisher Scientific (Illkirch, France). The PACAP (PACAP38) and the PACAP antagonist (PACAP6-38) were synthesized as previously described (Bourgault et al. 2009). tPA, PAI-1 and plasminogen were obtained from Calbiochem (Meudon, France).

\section{Animals}

Animals (male or female Wistar rats) were born and bred in an accredited animal facility (approval B.76-451-04), according to the French guide for the care and use of laboratory animals. Experiments were conducted under the supervision of authorized investigators (M.B, L.G., D.V. and H.V.) in accordance with the European Community Council Directive (2010/63/UE of September 22, 2010) and the French Ministry of Agriculture.

\section{Microexplants}

Microexplants were prepared from P2-P4 Wistar rat cerebella as previously described (Raoult et al., 2011). Into an incubation chamber $\left(37^{\circ} \mathrm{C}\right.$ and $\left.95 \% \mathrm{O}_{2}, 5 \% \mathrm{CO}_{2}\right)$ fixed to the stand an inverted microscope (IRE2, Leica Microsystems), transmitted light imaging 
Raoult et al, page 8

of $\mathrm{GN}$ was performed with using a $\times 16$ oil-immersion objective $(\mathrm{NA}=0.5)$. Images of migrating GN were collected every minute for $3 \mathrm{~h}$. Data were analyzed using Metamorph software (Roper Scientific, Evry, France).

\section{Immunohistochemistry}

After deep anesthesia (intraperitoneal injection of $400 \mathrm{mg} / \mathrm{kg}$ chloral hydrate), 10-dayold Wistar rats were perfused transcardially with phosphate-buffered saline (PBS; pH 7.4), followed by $4 \%$ paraformaldehyde in PBS. Brains were quickly dissected and postfixed overnight at $4^{\circ} \mathrm{C}$ with the same fixative solution. Tissues were stored for $24 \mathrm{~h}$ in a solution of PBS containing $15 \%$ and $30 \%$ sucrose, successively. Thereafter, tissues were cut at a thickness of $12 \mu \mathrm{m}$ in the sagittal plane with a cryostat (CM $3050 \mathrm{~S}$, Leica Microsystems). Tissue slices were mounted on glass slides coated with $0.5 \%$ gelatin and $5 \%$ chrome alun. After a 30 -min exposure with $1 \%$ BSA in PBS, the tissue sections were incubated for $2 \mathrm{~h}$ at room temperature with an antiserum raised in mouse against tPA (1 : 200, Abnova, Millipore, Molsheim, France) or/and an antiserum raised in rabbit against calbindin (1:500, Abnova, Millipore) containing $0.3 \%$ Triton X-100 and $1 \%$ BSA in PBS. The sections were rinsed in three successive baths of PBS and incubated for 2 $\mathrm{h}$ at room temperature with Alexa 488-conjugated goat anti-mouse $(1: 200$, Invitrogen) or/and Alexa 594-conjugated donkey anti-rabbit (1 : 200, Invitrogen) containing $0.3 \%$ Triton X-100 and 1\% BSA in PBS. The sections were then rinsed with PBS (3 times) and labeled for 1 min with 4'6-diamidino-2-phenylindole (DAPI, $2 \mu \mathrm{g} / \mathrm{mL}$ ) for nuclei counterstaining. After rinsing with PBS, the sections were mounted in PBS/glycerol (1 : 
Raoult et al, page 9

1, v/v). The preparations were examined on a Leica SP2 upright confocal laser scanning microscope (DM RXA-UV) equipped with Acousto-Optical Beam Splitter (AOBS) system. For confocal images, DAPI, Alexa 488 and Alexa 594 were excited respectively at 405, 488 and $594 \mathrm{~nm}$ and fluorescence signals were collected through the sequential mode.

\section{Interneuron migration in acute slice preparations}

Cerebella of 10-day-old Wistar rats were sectioned in the sagittal plane into $180 \mu \mathrm{m}$ thick slices with a vibrating blade microtome (VT1000S, Leica Microsystems) (Kumada et al. 2006; Cameron et al. 2007). To label interneurons, cerebellar slices were incubated for $5 \mathrm{~min}$ in $10 \mu \mathrm{M}$ Cell Tracker Green (CTG) (Invitrogen), which was added to the culture medium. The culture medium was composed of DMEM/ Ham's F12 with 1\% N2 supplement and 1\% antibiotic-antimycotic solution (Sigma-Aldrich). The slices were subsequently washed with culture medium, placed onto a polyester membrane insert from a 6-well plate and incubated in a $5 \% \mathrm{CO}_{2}$ atmosphere. Two to six hours after labeling, slices were transferred into an incubator attached to the stand of a confocal macroscope (TCS LSI, Leica Microsystems). The temperature of the chamber was kept at $37.0 \pm 0.5^{\circ} \mathrm{C}$ using a temperature controller (Tempcontrol 37-2 digital 2-channel, PeCon, Ulm, Germany), and the slices were supplied with constant gas flow $\left(95 \% \mathrm{O}_{2}\right.$, $5 \% \mathrm{CO}_{2} ; \mathrm{CO}_{2}$-controller, PeCon, Ulm, Germany). To visualize interneuron migration in the tissue slices, the preparation was illuminated with a 488-nm wavelength light by means of a laser diode through a confocal laser scanning macroscope equipped with a 
x2 dry objective (working distance: $39 \mathrm{~mm}$, diameter: $58 \mathrm{~mm}$, Leica Microsystems), and fluorescence emission was detected from 500 to $530 \mathrm{~nm}$. To finely resolve the movement of interneurons, images were acquired with an additional optical zoom factor of 1.5 to 2.0. Images of GN in a single focal plane or up to 10 different focal planes along the z-axis were collected every $30 \mathrm{~min}$ for up to $5 \mathrm{~h}$. Distinction of CTG-labeled GN and BS/C were based on their centripetal and centrifugal radial migration, respectively. For this reason, GN migration was studied in the ML, PCL and IGL while $\mathrm{B} / \mathrm{SC}$ analysis was restricted to the ML. Since immature basket and stellate cells cannot be morphologically distinguished, they were collectively identified as BS/C. Data were analyzed using ImageJ $(\mathrm{NIH})$.

\section{Statistical analysis}

All data are expressed as the mean \pm SEM value from three to seven independent experiments. Statistical analyses were conducted using a Kruskal-Wallis test or by the Mann-Whitney test using PRISM software (GraphPad Software, San Diego, CA, USA). 


\section{Results}

\section{Effect of PACAP, tPA, PAI-1 and plasminogen on isolated rat GN}

Using microexplant cultures from P2 to P4 rat cerebella, a preparation in which isolated GN actively migrate out of the tissue in the absence of cell to cell contacts (Yacubova and Komuro 2002a), we first examined whether PACAP and components of the tPAdependent proteolytic cascade can affect directly and independently GN migration. Application of PACAP $\left(10^{-6} \mathrm{M}\right)$ for $2 \mathrm{~h}$ significantly reduced GN motility by $70 \%$ (from 90 $\pm 5.4 \mu \mathrm{m} / \mathrm{h}$ to $27.3 \pm 5.4 \mu \mathrm{m} / \mathrm{h}$; Fig. 1$)$. Application of tPA $\left(10^{-7} \mathrm{M}\right)$ for $2 \mathrm{~h}$ did not alter GN velocity $(79.2 \pm 3.6 \mu \mathrm{m} / \mathrm{h}$ vs $75.4 \pm 7.3 \mu \mathrm{m} / \mathrm{h}$; Fig. 2a). Administration of plasminogen (a substrate of tPA; $10^{-7} \mathrm{M} ; 2 \mathrm{~h}$ ) did not significantly modify GN motility (from $79.6 \pm 1.6 \mu \mathrm{m} / \mathrm{h}$ vs $68.8 \pm 3.9 \mu \mathrm{m} / \mathrm{h}$ ) (Fig. 2b). Similarly, incubation of $\mathrm{GN}$ with PAI-1 (10 $\left.10^{-7} \mathrm{M}\right)$, an inhibitor of tPA had no effect on cell motility (Fig. 2c). Taken together, these results indicate that application of exogenous PACAP directly slows down the migration of rat GN while members of the tPA-dependent proteolytic cascade do not exert a direct control of GN motility in vitro.

\section{Distribution of tPA in cerebellar cortical layers of P10 rat}

Previous reports have described the distribution of PACAP in the rat and mouse developing cerebellum by in situ hybridization and immunohistochemistry (Nielsen et al. 1998; Hannibal 2002; Cameron et al. 2007). These studies have shown that PACAP is mainly expressed in the soma and dendrites of Purkinje cells and in mossy fiber terminals in the IGL (Cameron et al. 2007). In contrast, the distribution of TPA in the 
developing cerebellum has only been investigated at the mRNA level (Friedman and Seeds 1995; Ware et al. 1995). Therefore, we performed immunohistochemical staining with mouse polyclonal antibodies to localize endogenous tPA in the P10 rat cerebellum. Multi-labelings with the nuclear probe DAPI and with calbindin antibodies were also conducted to determine which cortical cerebellar layers and which cellular structures were tPA-positive. The EGL was virtually devoid of tPA immunoreactive signal (Fig. 3bd). In the ML, dendrites of Purkinje cells, surrounding DAPI-positive interneuron nuclei and the EM were moderately labeled with tPA antibodies (Fig. 3a-d). Intense tPA-like immunoreactivity was observed in the PCL, the IGL and the white matter (WM) of the cerebellum (Fig. 3b-d). In the PCL, tPA-positive material was detected in the EM and in large soma of Purkinje cells (Fig. 3a-d). Throughout the IGL, intense tPA staining was seen in the EM and in most small DAPI-positive cell bodies (Fig. 3b-d). Collectively, these results indicate the existence of various endogenous sources of IPA and a cortical layer specific expression of tPA in the early postnatal rat cerebellum.

\section{Effect of PACAP on centripetal migration of rat GN}

To investigate whether PACAP affects the migration of rat granule cells in their natural microenvironment, P10 acute rat cerebellar tissue slices labeled with the CTG fluorescent dye were examined under a confocal macroscope. Addition of exogenous PACAP38 $\left(10^{-6} \mathrm{M}\right)$ to the culture medium induced an immediate and strong decrease of the GN migration velocity in the ML (Fig. 4a). For example, the migration speed of GN in the $\mathrm{ML}$, marked (*) and (\#) in Fig. 4a, dropped from $14.5 \mu \mathrm{m} / \mathrm{h}$ and $12.3 \mu \mathrm{m} / \mathrm{h}$ in control 
conditions to $0.8 \mu \mathrm{m} / \mathrm{h}$ and $6.4 \mu \mathrm{m} / \mathrm{h}$ after application of $10^{-6} \mathrm{M}$ PACAP38, respectively (Fig. 4b, c). Globally, the average migration speed of $G N$ in the $M L$ decreased from 9.1 $\pm 0.4 \mu \mathrm{m} / \mathrm{h}(\mathrm{n}=22)$ in control conditions to $2.6 \pm 0.2 \mu \mathrm{m} / \mathrm{h}(\mathrm{n}=44)$ after PACAP treatment (Fig. 4d). Remarkably, PACAP38 $\left(10^{-6} \mathrm{M}\right)$ induced a $71 \%$ decrease of the migration speed of GN in the ML (Fig. 4d), and a 70\% decrease of the migration speed in microexplants (Fig. 1b). These data indicate that the effect of exogenous PACAP on GN migration in slices was similar to that observed in microexplant cultures, which suggests that PACAP slows GN migration in the ML directly via activation of its receptors on the plasmalemmal surface of the cells. Previous studies have indicated that endogenous PACAP is responsible for the transient arrest phase of mouse $G N$ in the PCL (Cameron et al. 2007). The potent PACAP antagonist, PACAP6-38, (Robberecht 1992), was thus used to examine the role of endogenous PACAP38 in the control of GN migration in the PCL of early postnatal rat cerebellum. Application of PACAP6-38 $\left(10^{-6} \mathrm{M}\right)$ to the culture medium increased the speed of GN migration by $23 \%$ at the level of the PCL (Fig. 4d), indicating that the slowdown of GN migration observed in the PCL of the early postnatal rat cerebellum is caused by endogenous PACAP38 through the activation of its receptors.

\section{Effect of tPA on centripetal migration of rat GN}

In the early postnatal cerebellum, granule cells exhibit significant changes in their migration speed as they cross different cortical layers (Komuro and Rakic 1995, 1998; Komuro et al. 2001; Komuro and Yacubova 2003; Kumada and Komuro 2004). The 
question was to know whether tPA could play a role in these cortical layer-specific changes of GN velocity during their migration process. The average speed of $\mathrm{GN}$ as they migrate through the $M L$ was $9.6 \pm 0.9 \mu \mathrm{m} / \mathrm{h}$ in control and $8.3 \pm 0.9 \mu \mathrm{m} / \mathrm{h}(\mathrm{n}=20)$ after addition of tPA $\left(10^{-7} \mathrm{M}\right)$ to the culture medium (Fig. 5a) indicating that exogenous tPA did not affect GN migration in the ML. In contrast, application of PAI-1, an inhibitor

of endogenous tPA, inhibited GN migration in a layer specific manner. Thus, PAI-1 (10 ${ }^{-7}$ M) markedly slowed down GN migration in the ML (Fig. 5b). For example, the granule cell marked $(*)$ in Fig. $5 \mathrm{~b}$ reduced its migration speed in the $\mathrm{ML}$ from $14.2 \mu \mathrm{m} / \mathrm{h}$ in control conditions to $2.7 \mu \mathrm{m} / \mathrm{h}$ after addition of PAl-1(Fig. 5c). Globally, in the presence of PAl-1 $\left(10^{-7} \mathrm{M}\right)$, the migration speed of granule cells was reduced by $70 \%$ in the $\mathrm{ML}$ and by $27 \%$ in the PCL but stayed unchanged in the IGL (Fig. $5 d$ ). These results indicate that, in the early postnatal rat cerebellum, endogenous tPA participates to GN migration in the ML and PCL but not in the IGL, despite the fact that IPA is present in the three different layers.

\section{Effect of tPA on centrifugal migration of rat B/SC}

To investigate whether IPA and PACAP affect the centrifugal migration of rat basket/stellate cells in the ML, P10 rat cerebellar tissue slices labeled with the CTG fluorescent dye were examined under a confocal macroscope (Fig. 6a). Although many B/SC were scattered throughout the ML, the density of CTG-labeled B/SC ( $n=306 \pm 79$ cell/ $/ \mathrm{mm}^{2}$ of ML) is much lower than that of CTG-labeled GN ( $\mathrm{n}=1124 \pm 138 \mathrm{cell} / \mathrm{mm}^{2}$ of ML) (Fig. 6b). Most B/SC (90\%; $n=91)$ migrate radially towards the top of the ML while 
only $10 \%(n=10)$ migrate obliquely, reaching nevertheless the interface between the ML and the EGL (data not shown). Among B/SC that move radially in the ML, two types of migration speed profiles were observed in control conditions (Fig. 6c); i.e. $68 \%$ of the tracked cells had an average speed of $9 \pm 0.4 \mu \mathrm{m} / \mathrm{h}(\mathrm{n}=65)$ and were defined as slow cells, while $32 \%$ of the cells displayed a migration speed of $15.6 \pm 0.5 \mu \mathrm{m} / \mathrm{h}(\mathrm{n}=26)$ and were defined as fast cells. Both categories of cells had saltatory movements (Fig. 6d) and reached the top of the $M L$ at the interface with the EGL. Following the same radial route, slow or fast B/SC intersect GN during their opposite migration in the ML (Fig. 7). After crossing a B/SC, GN often reduced their speed whereas the speed of B/SC was not affected by the presence of GN (Fig. 7a). B/SC can cross several GN (Fig. 7b) during their centrifugal move, suggesting they share a common interneuron rail to guide their migration. Application of PACAP6-38 $\left(10^{-6} \mathrm{M}\right)$ did not significantly affect the average speed of slow $(8.1 \pm 0.4 \mu \mathrm{m} / \mathrm{h} ; \mathrm{n}=25)$ and fast $(16 \pm 1.1 \mu \mathrm{m} / \mathrm{h} ; \mathrm{n}=7) \mathrm{B} / \mathrm{SC}$ nor their proportion (76\% and 24\%) (Fig. 8a), suggesting that endogenous PACAP does not interfere with $\mathrm{B} / \mathrm{SC}$ migration in the $\mathrm{ML}$. In contrast, PAI-1 $\left(10^{-7} \mathrm{M}\right)$ increased to $94 \%$ $(n=68)$ the proportion of slow migrating cells, so that only a few fast B/SC could still be observed $(6 \% ; n=7)$ (Fig. 8a). Treatment with PAl-1 $\left(10^{-7} \mathrm{M}\right)$ did not affect the migration of slow BS/C in the ML. For example, the migration speed of slow BS/C in the ML was similar in control conditions $(10.3 \mu \mathrm{m} / \mathrm{h})$ or after application of tPA $\left(10^{-7} \mathrm{M} ; 11.6 \mu \mathrm{m} / \mathrm{h}\right.$; Fig. $8 \mathrm{~b})$ whereas PAI-1 $\left(10^{-7} \mathrm{M}\right)$ strongly reduced the migration speed of fast $\mathrm{BS} / \mathrm{C}$ in the $\mathrm{ML}$ from $16.8 \mu \mathrm{m} / \mathrm{h}$ in control conditions to $7.3 \mu \mathrm{m} / \mathrm{h}$ (Fig. $8 \mathrm{c}$ ). 
Raoult et al, page 16

\section{Discussion}

The cerebellar cortex of rodents undergoes major changes during the first 4 postnatal weeks (Altman and Bayer 1997). Excitatory (GN) and inhibitory (B/SC) interneurons, with distinct embryological origins and opposite migration directions, populate the IGL and the ML, respectively, between P0 and P21 and control Purkinje cell activities in adult (Consalez and Hawkes 2013). Here, we report for the first time the direct inhibitory effect of PACAP on GN movements and the facilitatory role of the serine protease tPA on both $\mathrm{GN}$ and fast $\mathrm{B} / \mathrm{SC}$ migration in specific cortical cell layers of the developing rat cerebellum.

Using microexplant cultures, the present study revealed that application of exogenous PACAP reduces by $70 \%$ the migration speed of rat GN while tPA, plasminogen (a tPA substrate) or PAI-1 (a tPA inhibitor) do not alter GN motility in vitro. We have previously shown that PACAP stimulates tPA release from GN and that the inhibitory effect of PACAP on rat GN movement is not affected by PAI-1 or plasminogen pre-incubation (Raoult et al. 2011). Altogether, these data indicate that PACAP exerts a direct inhibitory effect on rat GN while tPA, and probably PACAP-induced tPA release, is likely to promote indirectly neuronal migration through proteolytic degradation of the EM. In support of this hypothesis, tPA is concentrated in leading processes of mouse GN during cerebellar development (Krystosek and Seeds 1981a,b; Seeds et al. 1997) where it facilitates GN migration (Seeds et al. 1999).

While the distribution pattern of PACAP in the postnatal cerebellum is now well established (Nielsen et al. 1998; Hannibal 2002; Cameron et al. 2007), the localization 
of the tPA protein is still unknown since the cellular expression of tPA has only been investigated by in situ hybridization experiments (Friedman and Seeds 1995; Ware et al. 1995). The present study revealed that tPA-like immunoreactivity is widely distributed in the ML, the PCL, the IGL and the WM of the cerebellum of P10 rats. In contrast, the EGL was virtually devoid of immunoreactive signal. The intense labeling observed in the EM in the different cortical layers of the cerebellum strengthens the possible contribution of tPA in the control of neuronal migration through its proteolytic activity. Several cell types could be the source of tPA since Purkinje cells and numerous small cell bodies, including possibly granule cells, were immunolabeled. The distribution of tPA-immunoreactive material is consistent with previous studies indicating the presence of tPA mRNA at the level of Purkinje cells and GN, but also in the IGL and the WM, during cerebellar development (Friedman and Seeds 1995; Ware et al. 1995). The detection of PACAP and tPA along the migratory routes of interneurons through the ML, PCL and IGL strongly suggested important roles for both factors in the control of GN and $\mathrm{B} / \mathrm{SC}$ movements. To test this hypothesis, we have investigated the effect of PACAP, tPA and PACAP-induced tPA release on interneuron migration in cerebellar slices, in which the cytoarchitecture remains intact, to study the proteolytic activity of tPA.

Time-lapse macroconfocal experiments revealed that exogenous PACAP38 slows down by $71 \%$ centripetal GN migration in the ML while the PACAP antagonist PACAP6-38 increases the speed of GN migration by $23 \%$ in the PCL. These results confirmed, ex vivo, the direct inhibitory effect of PACAP on rat GN migration observed in vitro and 
suggest that the decrease in speed of GN at the level of the PCL in the developing postnatal rat cerebellum is caused by endogenous PACAP through the activation of its G-protein-coupled receptors via cAMP- and $\mathrm{Ca}^{2+}$-dependent mechanisms as observed in mouse (Cameron et al. 2007, 2009a). Previous studies have revealed the contribution of tPA on GN migration in the ML of $\mathrm{tPA}^{-/-}$mice (Seeds et al. 1999) but the role of $\mathrm{TPA}$ in the PCL and the IGL had never been investigated. Using the model of cerebellar tissue slices, time-lapse macroconfocal imaging revealed that exogenous tPA does not alter GN migration in the ML while PAI-1 reduces the velocity of $\mathrm{GN}$ by $70 \%$ in the $\mathrm{ML}$ and by $27 \%$ in the PCL but has no effect in the IGL. Altogether, these data indicate that, in the early postnatal rat cerebellum, tPA favors $\mathrm{GN}$ migration not only in the ML as previously described (Seeds et al. 1999) but also in the PCL. Thus, we have shown that endogenous tPA contributes to the glia-dependent radial migration of GN in the ML and to the glia-independent radial migration of GN in the PCL. Since both PACAP and tPA have been found to be involved in cell migration within the PCL, we suggest that the stimulatory effect of PACAP on tPA secretion from GN, previously reported in vitro (Raoult et al. 2011), takes place at the level of the PCL and that this secretion of TPA induced by PACAP could contribute to the resumption of GN migration toward the IGL after their transient arrest at the level of the PLC. During postnatal development of the cerebellum, this pause of GN is well established but its functional significance remains unknown. Transient arrest phases of various duration appear to be a frequent feature of neuronal migration in brain histogenesis (Noctor et al. 2004). For instance, pyramidal neurons stop their migration for $24 \mathrm{~h}$ in the intermediate zone before attaining the 
cortical plate (Kriegstein and Noctor 2004). GABAergic interneurons first reach the ventricular zone of the cortex where they stay for a short time (45 min) and receive layer information that are essential for their final migration toward the cortical plate (Nadarajah et al. 2002). Since PACAP is involved in neuritogenesis (Gonzalez et al. 1997; Falluel-Morel et al. 2005), the transient arrest phase could be necessary for the initiation of a differentiation program and/or for a correct integration of GN in the IGL. As an example, somatostatin is the stop signal for GN in the IGL but the subtype of receptor that mediates the inhibitory effect on $\mathrm{GN}$ migration is a still matter of debate (Viollet et al. 1997; Yacubova and Komuro 2002b). In fact, somatostatin stimulates the tangential migration of $\mathrm{GN}$ in the EGL through sst2 receptors but exerts an opposite effect in the IGL through a different type of receptor. Thus, PACAP could be responsible for the switch of somatostatinergic control of GN migration by stimulating the recruitment and/or expression of new sst receptor subtype(s) or by modulating their transduction mechanisms (Goth et al. 1992). In the IGL, endogenous PACAP and tPA do not regulate the glia-independent radial migration of GN but are likely to play a neurotrophic action. Previous studies have shown that GN, without proper trophic support from glutamatergic mossy fibers, die by apoptosis in the IGL (Williams and Herrup 1988; Wood et al. 1993). PACAP is contained in mossy fibers (Cameron et al. 2007) and promotes in vitro GN survival through the release of tPA (Raoult et al. 2011). In addition, the thickness of the IGL is significantly reduced at P7 in PACAP-knockout $\left(\mathrm{PACAP}^{--}\right)$mice (Allais et al. 2007). Taken together, these data strongly suggest the 
Raoult et al, page 20

contribution of PACAP-induced tPA secretion to the neuroprotective effect of PACAP in the IGL.

While GN migrate from the EGL toward the IGL, basket and stellate cells migrate from the WM to reach the inferior or superior part of the ML, respectively (Rakic 1973; Zhang and Goldman 1996; Yamanaka et al. 2004; Leto et al. 2006; Cameron et al. 2009). In this study, we referred to basket cells and stellate cells as immature basket/stellate cells (B/SC), and analyzed their radial centrifugal migration in the $\mathrm{ML}$ as a single cell type because they are morphologically indistinguishable (Cameron et al. 2009). However, we cannot rule out the possibility that basket cells and stellate cells exhibit some differences in their speed and regulation of migration. In the P10 ML, we have determined the low density of migrating labeled B/SC compare to GN density. As in mouse (Cameron et al. 2009), a large majority (90\%) of BS/C displayed a radial migration while only $10 \%$ of the cells migrated obliquely toward the top of the ML. In the $\mathrm{ML}$, two types of B/SC have been identified for the first time according to their radial migration speed and designated as slow (68\%) and fast (32\%) cells. Both slow and fast cells reached the top of the ML with saltatory movements as previously described in mouse (Cameron et al. 2009). As a new concept in cerebellar interneuron migration, we have shown that slow and fast BS/C intersect with GN, suggesting that they share a common migratory rail in the $\mathrm{ML}$ and that some $\mathrm{GN}$ tend to slow down after crossing B/SC. In the presence of PAI-1, 94\% of B/SC exhibited a slow profile, indicating that endogenous tPA participates to the radial centrifugal migration of fast cells while the 
migration of slow cells is independent of tPA. Both Purkinje cells and GN (Friedman and Seeds 1995; Raoult et al. 2011, this study) express tPA and could therefore release tPA in the EM to facilitate the migration of fast cells. Several hypotheses have been proposed for B/SC guiding along the migration routes. B/SC movements could be facilitated along GN axons as well as Purkinje cell axons, climbing fibers and mossy fibers through cell to cell contacts (Guijarro et al. 2006; Cameron et al. 2009). Since radial centripetal migration of GN in the ML depends on both tPA (Seeds et al. 1999, this study) and glial fibers (Komuro and Rakic 1998), Bergmann glial processes may also serve as a scaffold for radial migration of $B / S C$ in the ML through a tPA-dependent mechanism. Whether differences in the speed and regulation of migration discriminate slow and fast cells as basket and stellate cells or vice versa is still a matter of debate since subtypes of basket and/or stellate cells may also exist (Consalez and Hawkes 2013).

At the top of the ML, a high density of immature $\mathrm{B} / \mathrm{SC}$ has been described suggesting that they sojourn next to the EGL before they ultimately translocate to the middle part of the ML (Weisheit et al. 2006) and that this is a necessary step for their differentiation and proper distribution. At present, little is known regarding the possible regulators of BS/C migration except that inhibitory interneurons display repulsive behavior against Netrin1 which is abundant in the EGL during the early postnatal period (Alcantara et al. 2000; Guijarro et al. 2006). Here, we show that PACAP does not affect the radial centrifugal migration of B/SC in the ML. The observation that PACAP6-38 had no effect on $\mathrm{B} / \mathrm{SC}$ migration indicates that tPA-induced promotion of fast cell movement is also 
independent of PACAP. PACAP usually exerts dual effects on neural/glial cells i.e. inhibition of migration and stimulation of differentiation. Consistent with this notion, the PACAP/PAC1 system promotes stellate morphology in astrocytes (Nishimoto et al. 2007). PACAP could therefore be involved in the completion of B/SC migration in the middle of the ML, where inhibitory interneurons extend dendrite-like processes (Cameron et al. 2009). Interestingly, B/SC did not stop in the PCL in contrast to GN that exhibit a PACAP-dependent arrest phase of approximately 2 hours (Cameron et al. $2007,2009)$. This suggests that $\mathrm{GN}$ and $\mathrm{B} / \mathrm{SC}$ require, along their migratory route, a cortical layer-specific "stand by" phase before their correct and final integration. This pause phase would be necessary for the initiation of intrinsic programs that may control expression of the receptors which recognize final external stop signals or initiate the differentiation program.

In conclusion, our data indicate for the first time that, during the second post-natal week in the rat cerebellum, $\mathrm{GN}$ and $\mathrm{B} / \mathrm{SC}$ migrate radially along Bergmann fibers but in opposite directions, crossing each other in the ML. In the ML, through degradation of the EM, tPA exerts a central role facilitating centripetal and centrifugal migration of GN and fast B/SC, respectively. PACAP is responsible for the transient arrest phase of migrating $\mathrm{GN}$ in the PCL, and PACAP-induced tPA release could therefore stimulate the resumption of GN migration to reach their final position in the IGL. 
Raoult et al, page 23

\section{Acknowledgments}

This work was supported by, the Institute for Research and Innovation in Biomedicine (IRIB), the Cell Imaging Platform of Normandy (PRIMACEN), INSERM, the FEDER (\# 2517) and Interreg 4A TC2N european programs, the LARC-Neurosciences Network and the Région Haute-Normandie. E.R. was the recipient of a doctoral fellowship from the LARC-Neuroscience Network and the Région Haute-Normandie. D.V. and H.V. are Affiliated Professors at the Institut National de la Recherche Scientifique — Institut Armand-Frappier. The authors declare no competing financial interests. 


\section{References}

Alcantara S., Ruiz M., De Castro F., Soriano E. and Sotelo C. (2000) Netrin 1 acts as an attractive or as a repulsive cue for distinct migrating neurons during the development of the cerebellar system. Development 127, 1359-1372.

Allais A., Burel D., Isaac E. R., Gray S.L., Basille M., Ravni A., Sherwood N. M., Vaudry H. and Gonzalez B. J. (2007) Altered cerebellar development in mice lacking pituitary adenylate cyclase-activating polypeptide. Eur. J. Neurosci. 25, 26042618.

Altman J. and Bayer S. A. (1997) Development of the cerebellar system in relation to its evolution, structure, and functions. Boca Raton FL: CRC Press.

Basham M. E. and Seeds N. W. (2001) Plasminogen expression in the neonatal and adult mouse brain. J. Neurochem. 77, 318-325.

Bourgault S., Vaudry D., Segalas-Milazzo I., Guilhaudis L., Couvineau A., Laburthe M., Vaudry H. and Fournier A. (2009) Molecular and conformational determinants of pituitary adenylate cyclase-activating polypeptide (PACAP) for activation of the PAC1 receptor. J. Med. Chem. 52, 3308-3316.

Cameron D. B., Galas L., Jiang Y., Raoult E., Vaudry D. and Komuro H. (2007) Cerebellar cortical-layer-specific control of neuronal migration by pituitary adenylate cyclase-activating polypeptide. Neuroscience 146, 697-712.

Cameron D. B., Kasai K., Jiang Y., Hu T., Saeki Y. and Komuro H. (2009a) Four distinct phases of basket/stellate cell migration after entering their final destination (the molecular layer) in the developing cerebellum. Dev. Biol. 332, 309-324. 
Cameron D. B., Raoult E., Galas L., Jiang Y., Lee K., Hu T., Vaudry D. and Komuro H. (2009b) Role of PACAP in controlling granule cell migration. Cerebellum 8, 433440.

Consalez G. G. and Hawkes R. (2012) The compartmental restriction of cerebellar interneurons. Front. Neural. Circuits. 6, 123.

Evsyukova I., Plestant C. and Anton E. S. (2013) Integrative mechanisms of oriented neuronal migration in the developing brain. Annu. Rev. Cell Dev. Biol. 29, 299353.

Falluel-Morel A., Vaudry D., Aubert N., Galas L., Bénard M., Basille M., Fontaine M., Fournier A, Vaudry H and Gonzalez B. J. (2005) Pituitary adenylate cyclaseactivating polypeptide prevents the effects of ceramides on migration, neurite outgrowth, and cytoskeleton remodeling. Proc. Natl. Acad. Sci. USA 102, 26372642.

Flint A. C. and Kriegstein A. R. (1997) Mechanisms underlying neuronal migration disorders and epilepsy. Curr. Opin. Neurol. 10, 92-97.

Friedman G. C. and Seeds N.W. (1995) Tissue plasminogen activator mRNA expression in granule neurons coincides with their migration in the developing cerebellum. J. Comp. Neurol. 360, 658-670.

Garcia-Rocha M., Avila J. and Armas-Portela R. (1994) Tissue-type plasminogen activator (tPA) is the main plasminogen activator associated with isolated rat nerve growth cones. Neurosci. Lett. 180, 123-126. 
Gonzalez B. J., Basille M., Vaudry D., Fournier A. and Vaudry H. (1997) Pituitary adenylate cyclase-activating polypeptide promotes cell survival and neurite outgrowth in rat cerebellar neuroblasts. Neuroscience 78, 419-430.

Goth M. I., Lyons C. E., Canny B. J. and Thorner M. O. (1992) Pituitary adenylate cyclase activating polypeptide, growth hormone $(\mathrm{GH})$-releasing peptide and $\mathrm{GH}$ releasing hormone stimulate $\mathrm{GH}$ release through distinct pituitary receptors. Endocrinology 130, 939-944.

Gressens P. (2006) Pathogenesis of migration disorders. Curr. Opin. Neurol. 19, 135140.

Guijarro P., Simo S., Pascual M., Abasolo I., Del Rio J.A. and Soriano E. (2006) Netrin1 exerts a chemorepulsive effect on migrating cerebellar interneurons in a Dccindependent way. Mol. Cell. Neurosci. 33, 389-400.

Hannibal J. (2002) Pituitary adenylate cyclase-activating peptide in the rat central nervous system: an immunohistochemical and in situ hybridization study. J. Comp. Neurol. 453, 389-417.

Hatten M. E. (1999) Central nervous system neuronal migration. Annu. Rev. Neurosci. 22, 511-539.

Komuro H. and Rakic P. (1995) Dynamics of granule cell migration: a confocal microscopic study in acute cerebellar slice preparations. J. Neurosci. 15, 11101120.

Komuro H. and Rakic P. (1998) Distinct modes of neuronal migration in different domains of developing cerebellar cortex. J. Neurosci. 18, 1478-1490. 
Komuro H., Yacubova E., Yacubova E. and Rakic P. (2001) Mode and tempo of tangential cell migration in the cerebellar external granular layer. J. Neurosci. 21, $527-540$.

Komuro H. and Yacubova E. (2003) Recent advances in cerebellar granule cell migration. Cell. Mol. Life Sci. 60, 1084-1098.

Kriegstein A. R. and Noctor S. C. (2004) Patterns of neuronal migration in the embryonic cortex. Trends Neurosci. 27, 392-399.

Krystosek A. and Seeds N.W. (1981a) Plasminogen activator release at the neuronal growth cone. Science 213, 1532-1534.

Krystosek A. and Seeds N. W. (1981b) Plasminogen activator secretion by granule neurons in cultures of developing cerebellum. Proc. Natl. Acad. Sci. USA 78, 7810-7814.

Kumada T. and Komuro H. (2004). Completion of neuronal migration regulated by loss of $\mathrm{Ca}(2+)$ transients. Proc. Natl. Acad. Sci. USA 101, 8479-8484.

Leto K., Carletti B., Williams I.M., Magrassi L. and Rossi F. (2006) Different types of cerebellar GABAergic interneurons originate from a common pool of multipotent progenitor cells. J. Neurosci. 26, 11682-11694.

Melchor J. P. and Strickland S. (2005) Tissue plasminogen activator in central nervous system physiology and pathology. Thromb. Haemost. 93, 655-660.

Milosevic A. and Goldman J. E. (2004) Potential of progenitors from postnatal cerebellar neuroepithelium and white matter: lineage specified vs. multipotent fate. Mol. Cell. Neurosci. 26, 342-353. 
Nadarajah B., Alifragis P., Wong R. O. and Parnavelas J. G. (2002) Ventricle-directed migration in the developing cerebral cortex. Nat. Neurosci. 5, 218-224.

Nielsen H. S., Hannibal J. and Fahrenkrug J. (1998) Expression of pituitary adenylate cyclase activating polypeptide (PACAP) in the postnatal and adult rat cerebellar cortex. Neuroreport 9, 2639-2642.

Nishimoto M., Furuta A., Aoki S., Kudo Y., Miyakawa H. and Wada K. (2007) PACAP/PAC1 autocrine system promotes proliferation and astrogenesis in neural progenitor cells. Glia 55, 317-327.

Noctor S. C., Martinez-Cerdeno V., Ivic L. and Kriegstein A. R. (2004) Cortical neurons arise in symmetric and asymmetric division zones and migrate through specific phases. Nat. Neurosci. 7, 136-144.

Rakic P. (1973) Kinetics of proliferation and latency between final cell division and onset of differentiation of cerebellar stellate and basket neurons. J. Comp. Neurol. 147, $523-546$.

Rakic P. (1988) Defects of neuronal migration and the pathogenesis of cortical malformations. Prog. Brain Res. 73, 15-37.

Rakic P. (1990) Principles of neural cell migration. Experientia 46, 882-891.

Raoult E., Roussel B. D., Bénard M., Lefebvre T., Ravni A., Ali C., Vivien D., Komuro H., Fournier A., Vaudry H., Vaudry D. and Galas L. (2011) Pituitary adenylate cyclase-activating polypeptide (PACAP) stimulates the expression and the release of tissue plasminogen activator (tPA) in neuronal cells: involvement of tPA in the neuroprotective effect of PACAP. J. Neurochem. 119, 920-931. 
Robberecht P., Gourlet P., De Neef P., Woussen-Colle M. C., Vandermeers-Piret M. C., Vandermeers A. and Christophe J. (1992) Receptor occupancy and adenylate cyclase activation in AR 4-2J rat pancreatic acinar cell membranes by analogs of pituitary adenylate cyclase-activating peptides amino-terminally shortened or modified at position 1, 2, 3, 20, or 21. Mol. Pharmacol. 42, 347-355.

Seeds N. W., Basham M. E. and Haffke S. P. (1999) Neuronal migration is retarded in mice lacking the tissue plasminogen activator gene. Proc. Natl. Acad. Sci. USA 96, $14118-14123$.

Seeds N. W., Siconolfi L. B. and Haffke S. P. (1997) Neuronal extracellular proteases facilitate cell migration, axonal growth, and pathfinding. Cell Tissue Res. 290, 367370.

Vaudry D., Falluel-Morel A., Bourgault S., Basille M., Burel D., Wurtz O., Fournier A., Chow B. K., Hashimoto H., Galas L. and Vaudry H. (2009). Pituitary adenylate cyclase-activating polypeptide and its receptors: 20 years after the discovery. Pharmacol. Rev. 61, 283-357.

Vaudry D., Gonzalez B. J., Basille M., Yon L., Fournier A. and Vaudry H. (2000) Pituitary adenylate cyclase-activating polypeptide and its receptors: from structure to functions. Pharmacol. Rev. 52, 269-324.

Viollet C., Bodenant C., Prunotto C., Roosterman D., Schaefer J., Meyerhof W., Epelbaum J., Vaudry H. and Leroux P. (1997) Differential expression of multiple somatostatin receptors in the rat cerebellum during development. J. Neurochem. 68, 2263-2272. 
Ware J. H., DiBenedetto A. J. and Pittman R. N. (1995) Localization of tissue plasminogen activator mRNA in the developing rat cerebellum and effects of inhibiting tissue plasminogen activator on granule cell migration. J. Neurobiol. 28, 9-22.

Weisheit G., Gliem M., Endl E., Pfeffer P. L., Busslinger M. and Schilling K. (2006) Postnatal development of the murine cerebellar cortex: formation and early dispersal of basket, stellate and Golgi neurons. Eur. J. Neurosci. 24, 466-478.

Williams R. W. and Herrup K. (1988) The control of neuron number. Annu. Rev. Neurosci. 11, 423-453.

Wood K. A., Dipasquale B. and Youle R. J. (1993) In situ labeling of granule cells for apoptosis-associated DNA fragmentation reveals different mechanisms of cell loss in developing cerebellum. Neuron 11, 621-632.

Yacubova E. and Komuro H. (2002a) Intrinsic program for migration of cerebellar granule cells in vitro. J. Neurosci. 22, 5966-5981.

Yacubova E. and Komuro H. (2002b) Stage-specific control of neuronal migration by somatostatin. Nature $415,77-81$.

Yamanaka H., Yanagawa Y. and Obata K. (2004) Development of stellate and basket cells and their apoptosis in mouse cerebellar cortex. Neurosci. Res. 50, 13-22.

Yepes M. and Lawrence D. A. (2004) Tissue-type plasminogen activator and neuroserpin: a well-balanced act in the nervous system? Trends Cardiovasc. Med. $14,173-180$. 
Raoult et al, page 31

Zhang L. and Goldman J. E. (1996) Generation of cerebellar interneurons from dividing progenitors in white matter. Neuron 16, 47-54. 
Raoult et al, page 32

\section{Legends to figures}

Fig. 1 PACAP slows down isolated GN. (a) Time-lapse imaging showing the inhibitory effect of PACAP $\left(10^{-6} \mathrm{M}\right)$ on an isolated $\mathrm{GN}$ escaping from a P4 cerebellum microexplant. After plating in glass bottom Petri dishes, GN were tracked by videomicroscopy for $1 \mathrm{~h}$ in control conditions and then for $2 \mathrm{~h}$ in the presence of PACAP. Asterisks mark the GN soma. Elapsed time (in min) is indicated at the bottom of each photomicrograph. Scale bar: $10 \mu \mathrm{m}$. (b) Sequential changes in the distance traveled by GN soma showing that PACAP $\left(10^{-6} \mathrm{M}\right)$ reduces $\mathrm{GN}$ movements immediately upon application. Results represent the mean \pm SEM (error bar) from $n=44$ determinations. The histograms represent the change in the average migration speed after application of PACAP: ${ }^{* * *} p<0.001$ versus control.

Fig. 2 Members of the tPA-dependent proteolytic cascade have no effect on GN motility. (a-c) Sequential changes in the distance traveled by GN soma showing that tPA $\left(10^{-7} \mathrm{M}\right)$, plasminogen $\left(10^{-7} \mathrm{M}\right)$ and PAl-1 $\left(10^{-7} \mathrm{M}\right)$ do not affect the migration speed of GN. Results represent the mean \pm SEM (error bar) from $n=88,114$ and 65 determinations, respectively. The histograms compare the average migration speed of GN before and after application of tPA (a), plasminogen (b) and PAI-1 (c). n.s., not statistically significant versus control.

Fig. 3 tPA immunoreactivity is widely distributed in cortical layers of P10 rat cerebellum. (a-d) Immunohistochemical localization of tPA in the early postnatal cerebellum. 
Raoult et al, page 33

Sagittal tissue sections from P10 rat cerebella were processed for tPA and calbindin immunohistochemistry as well as DAPI labeling before confocal microscopy imaging. (a) Overlay of double labeling for calbindin-like immunoreactivity and DAPI staining of nuclei allowing cortical layers demarcation and Purkinje cell localization. (b) Overlay of double labeling for tPA-like immunoreactivity and DAPI showing large staining of the extracellular matrix and numerous positive small cell bodies in the ML and the IGL. (c) Overlay of double labeling for tPA- and calbindin-like immunoreactivity indicating that Purkinje cell soma and dendrites are positive for tPA. (d) Overlay of triple labeling for DAPI, calbindin-like and tPA-like immunoreactivity at higher magnification illustrating the presence of tPA in the interstitial space. Scale bar $=30 \mu \mathrm{m}$.

Fig. 4 Endogenous PACAP reduces GN migration in P10 rat cerebellar slices. (a) Timelapse imaging showing that exogenous PACAP $\left(10^{-6} \mathrm{M}\right)$ slows down $\mathrm{GN}$ movements in the ML. GN were tracked by confocal macroscopy for $2 \mathrm{~h}$ in control conditions and then for $2 \mathrm{~h}$ in the presence of PACAP. Asterisk $\left(^{*}\right)$ and sharp (\#) symbols mark the GN soma. Elapsed time (in min) is indicated on the bottom of each photomicrograph. Scale bar $=10 \mu \mathrm{m} .(\mathrm{b}-\mathrm{c})$ Sequential changes in the distance traveled by GN soma showing that exogenous PACAP $\left(10^{-6} \mathrm{M}\right)$ inhibits rapidly the migration of $\left({ }^{*}\right)$ and $(\#)$ marked GN. (d) The histograms compare the average migration speed before and after application of PACAP $\left(10^{-6} \mathrm{M}\right)$ or the PACAP antagonist PACAP6-38 $\left(10^{-6} \mathrm{M}\right)$. Results represent the mean \pm SEM (error bar) from $n=66$ and $n=36$ determinations, respectively. ${ }^{*} p<0.5$; ${ }^{* * *} p<0.001$ versus control. 
Raoult et al, page 34

Fig. 5 Endogenous tPA participates to $G N$ migration in the $M L$ and $P C L$ of $P 10$ rat cerebellar slices. (a) Histograms showing that exogenous tPA $\left(10^{-7} \mathrm{M}\right)$ does not affect the migration speed of $\mathrm{GN}$ in the ML. GN were tracked by confocal macroscopy for $2 \mathrm{~h}$ in control conditions and then for $2 \mathrm{~h}$ in the presence of tPA. (b) Time-lapse imaging showing the inhibitory effect of PAI-1 $\left(10^{-7} \mathrm{M}\right)$ on $\mathrm{GN}$ movements in the ML. GN were tracked by confocal macroscopy for $2 \mathrm{~h}$ in control conditions and then for $2 \mathrm{~h}$ in the presence of PAI-1. Asterisk marks the GN soma. Elapsed time (in min) is indicated on the bottom of each photomicrograph. Scale bar $=10 \mu \mathrm{m}$. (c) Sequential changes in the distance traveled by GN soma showing that PAI-1 $\left(10^{-7} \mathrm{M}\right)$ immediately slows down GN migration in the ML. (d) Histograms showing that PAI-1 reduces the average migration speed of GN in the ML, the PCL but not in the IGL. Results represent the mean \pm SEM from $n=20, n=96$ and $n=32$ determinations, respectively. n.s., not statistically significant; ${ }^{*} p<0.5 ;{ }^{* * *} p<0.001$ versus control.

Fig. 6 Migrating B/SC exhibit two types of speed profiles in the ML. (a) Macroconfocal view of a P10 rat cerebellar slice in which CTG-labeled B/SC and GN are tracked every 30 min. Scale bar $=50 \mu \mathrm{m}$. (b) Histograms showing the low density of B/SC compared to the high density of GN in the ML. (c) Sequential changes in the distance traveled by B/SC soma showing that fast and slow cells can be identified in the ML. (d) Distance traveled by slow (black histograms) and fast (dotted-line histograms) B/SC during each 30-min acquisition period, illustrating the saltatory movements of both types of cells. 
Fig. $7 \mathrm{~B} / \mathrm{SC}$ and $\mathrm{GN}$ use common rail of migration in the ML. (a-b) Time-lapse imaging showing intersection of slow (a) and fast (b) B/SC with GN. BS and G/G mark B/SC and GN soma respectively. Bottom-up and top-down arrows indicate centrifugal and centripetal migration, respectively. Elapsed time (in min) is indicated under each photomicrograph. Scale bar $=5 \mu \mathrm{m}$.

Fig. 8 tPA participates to the migration of fast B/SC while PACAP has no effect on any B/SC. (a) Histograms showing that blockage of endogenous PACAP by the PACAP antagonist PACAP6-38 $\left(10^{-6} \mathrm{M}\right)$ has no effect on the proportion of slow (black histogram) and fast (dotted-line histogram) B/SC while blockade of endogenous tPA with PAI-1 markedly decreases the proportion of fast B/SC. (b) Sequential changes in the distance traveled by slow B/SC soma showing that PAI-1 $\left(10^{-7} \mathrm{M}\right)$ does not significantly modify the migration speed of slow cells in the ML. (c) Sequential changes in the distance traveled by fast $\mathrm{B} / \mathrm{SC}$ soma showing that PAI-1 $\left(10^{-7} \mathrm{M}\right)$ strongly slows down the migration of fast cells in the ML. Results represent the mean \pm SEM from $n=91$ (control), $n=32$ (PACAP(6-38)) and $n=75$ (PAI-1) determinations, respectively. n.s., not statistically significant; ${ }^{*} p<0.5$ versus control. 
(a)

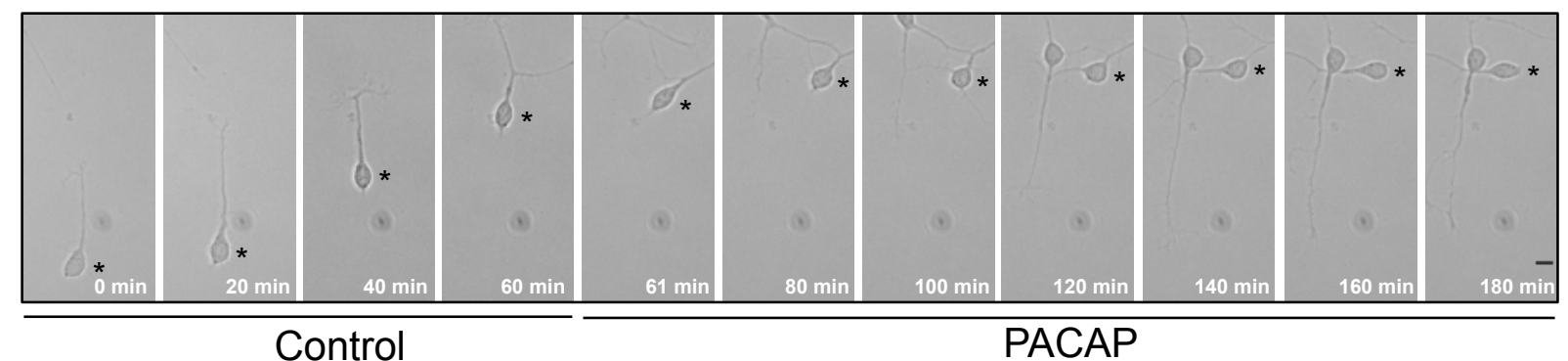

(b)
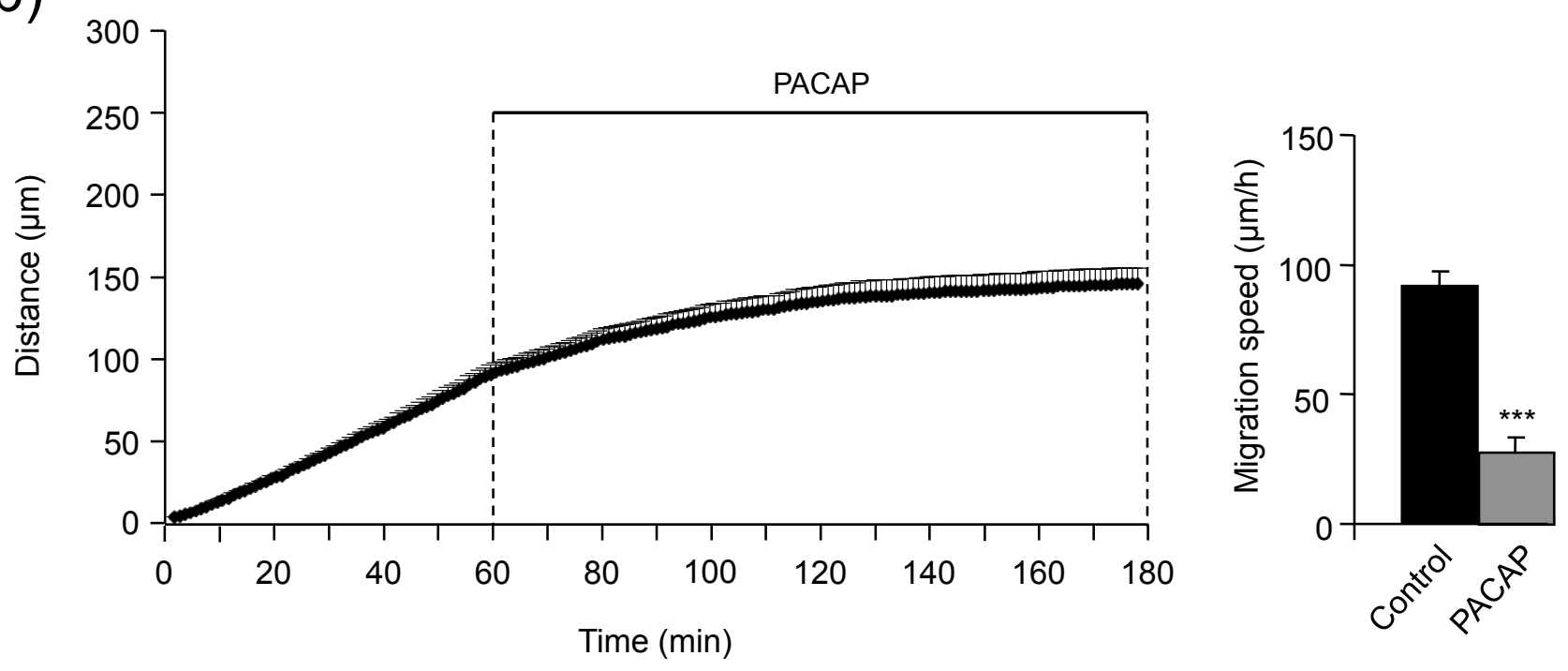

Fig. 1 
(a)
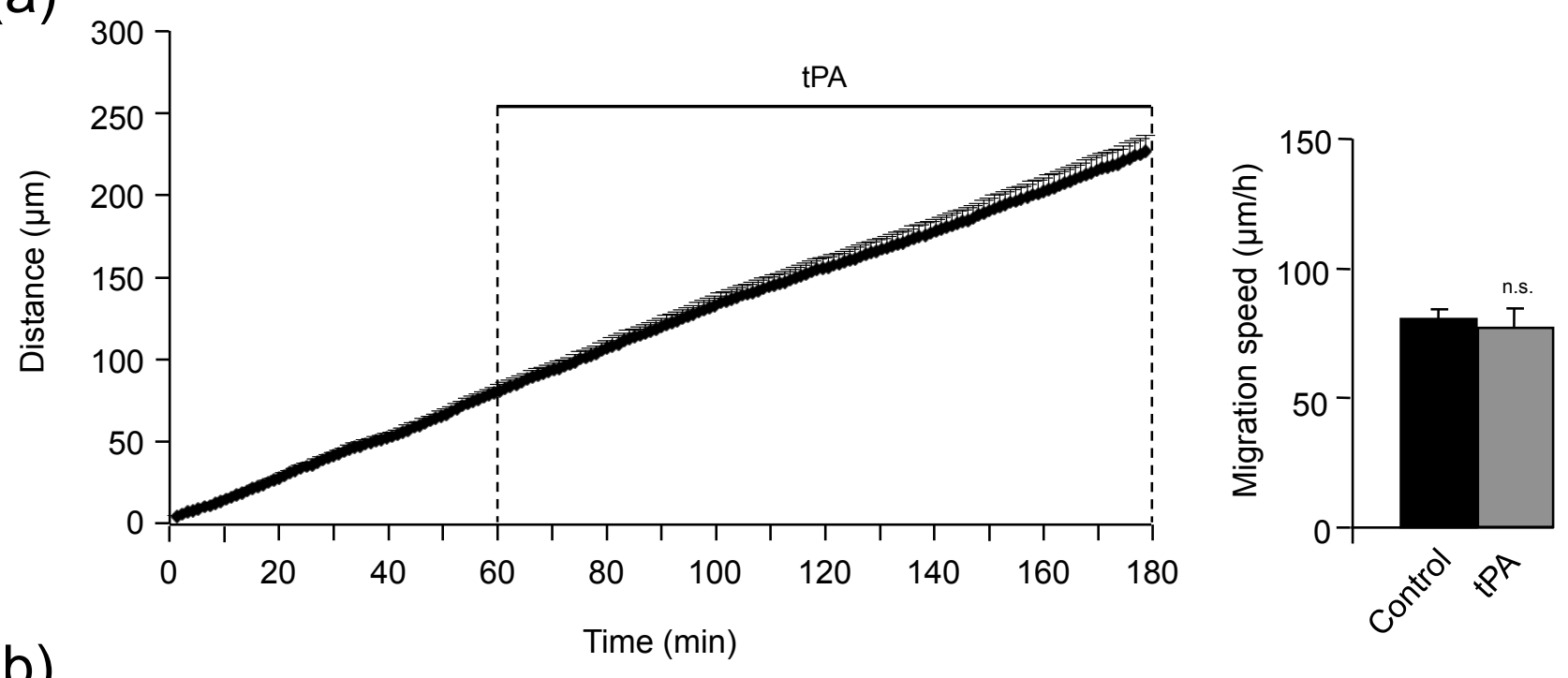

(b)

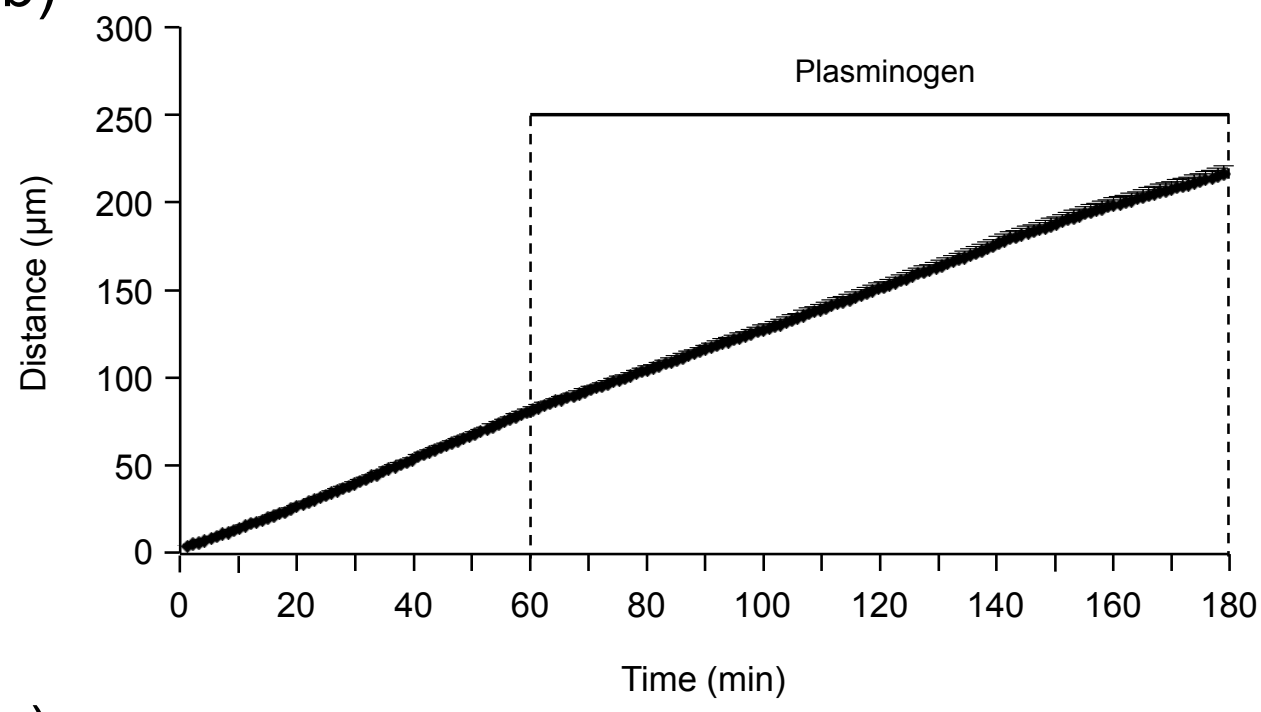

(c)
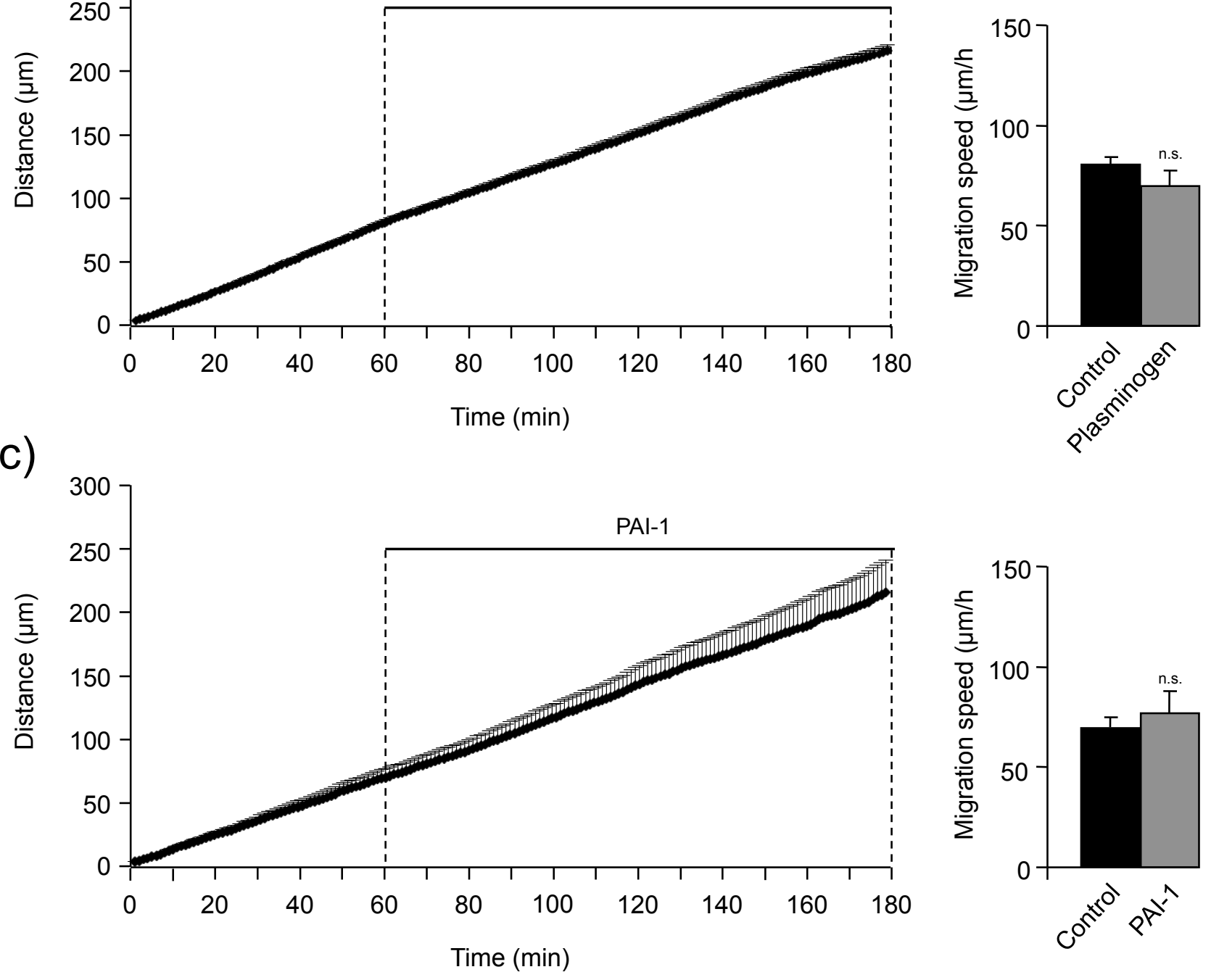

Fig. 2

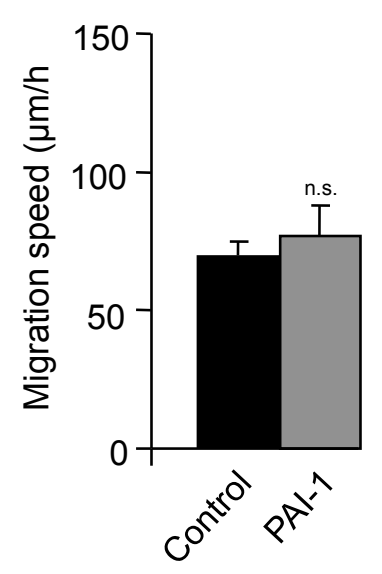

Raoult et al. 

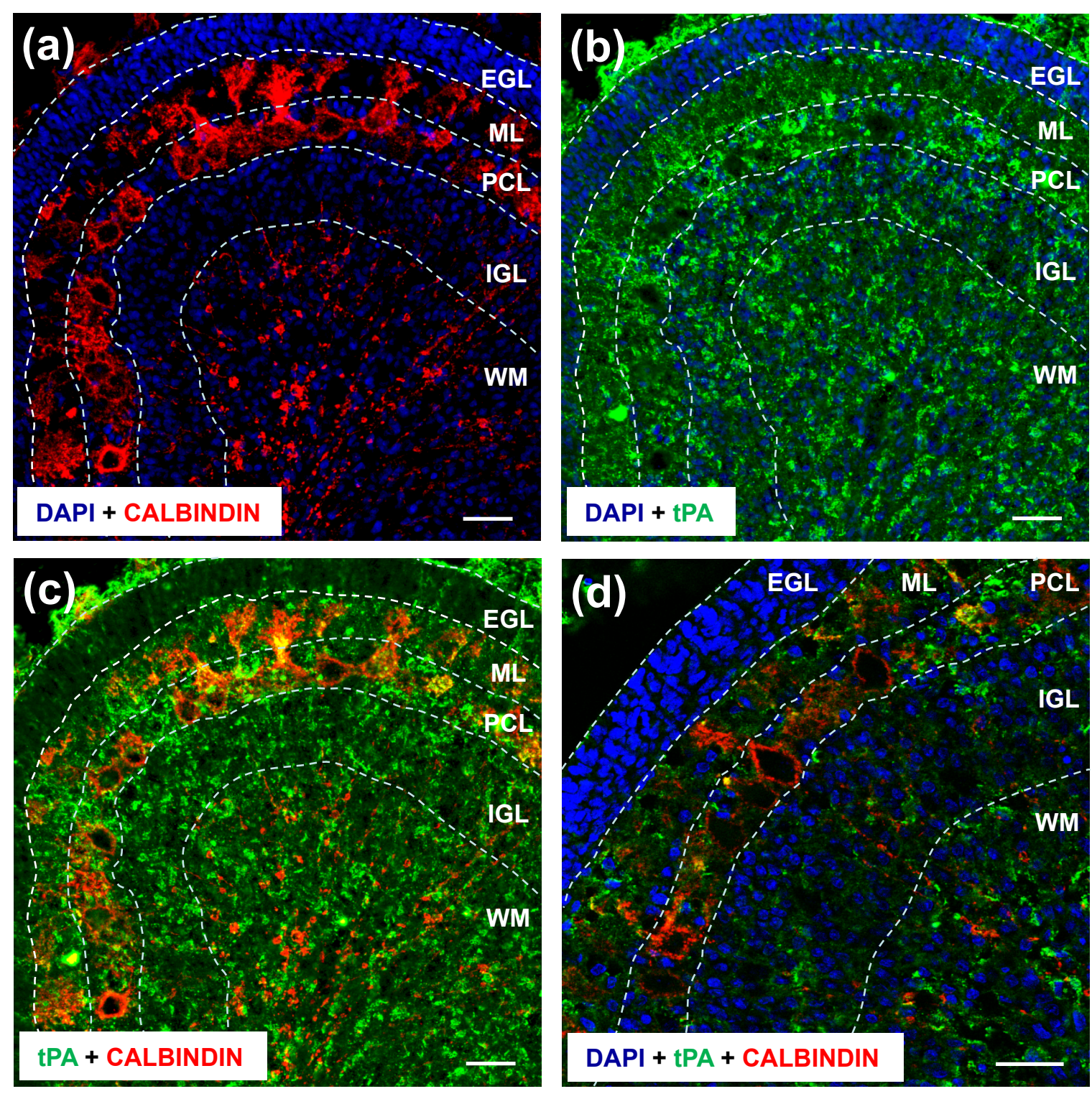

Fig. 3

Raoult et al. 
(a)

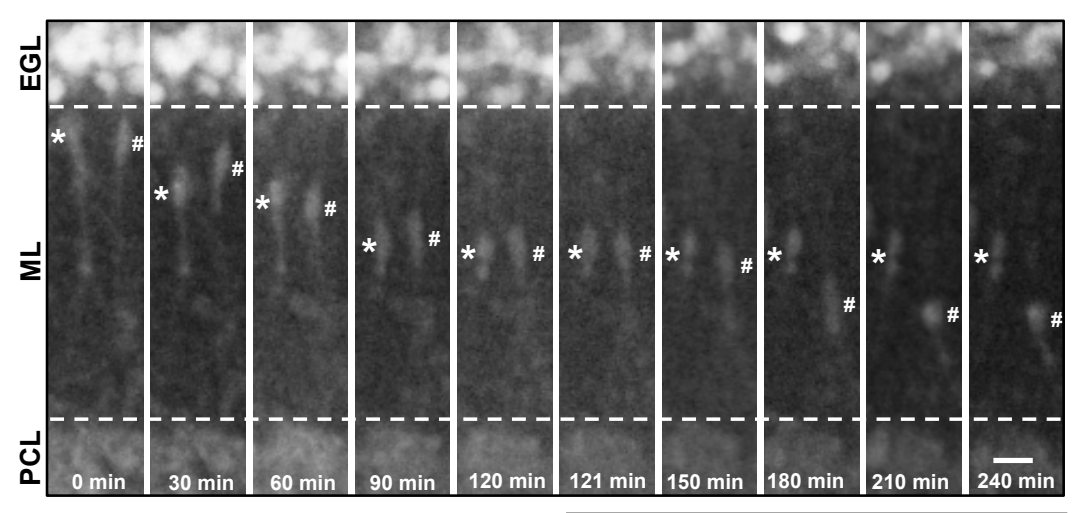

PACAP (d)

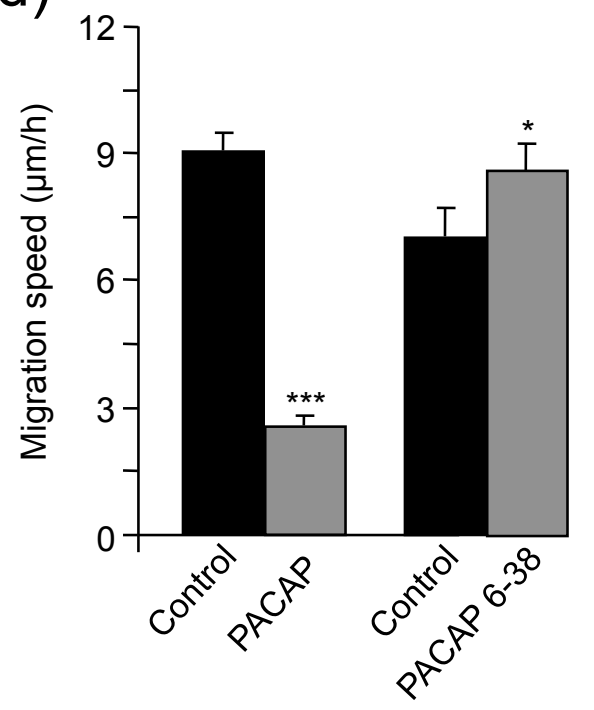

(b)

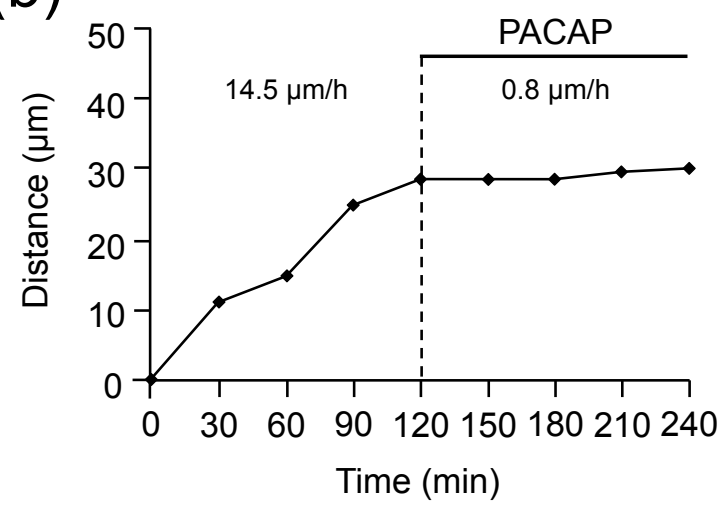

(c)

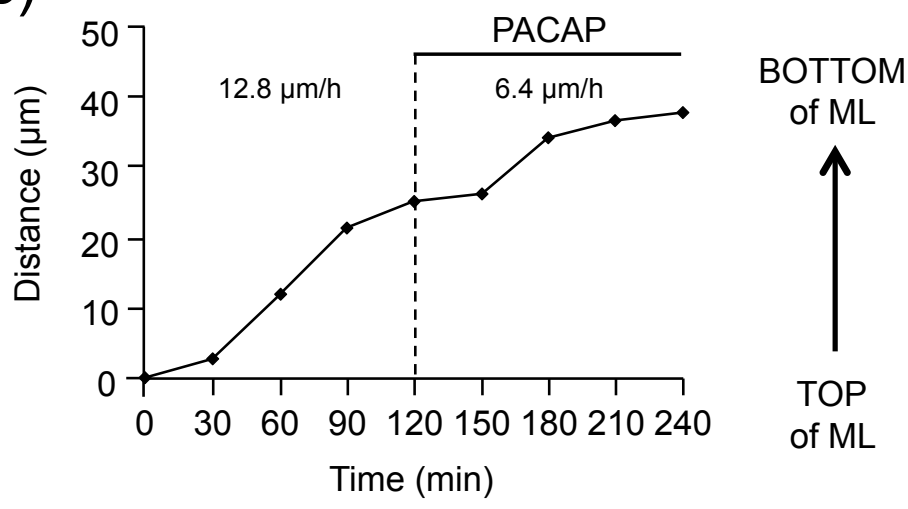

Fig. 4 
(a)

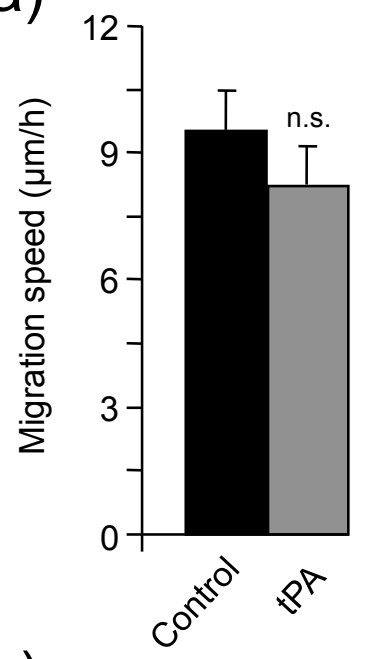

(c)

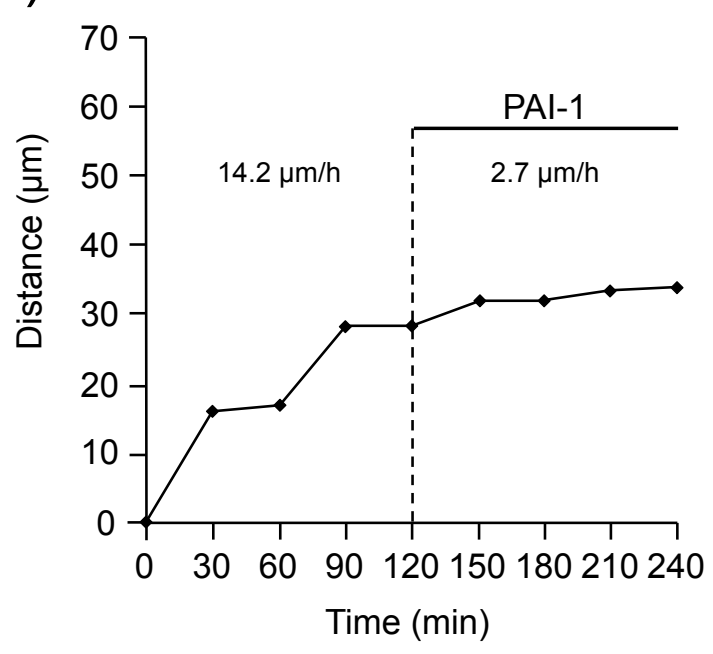

(b)

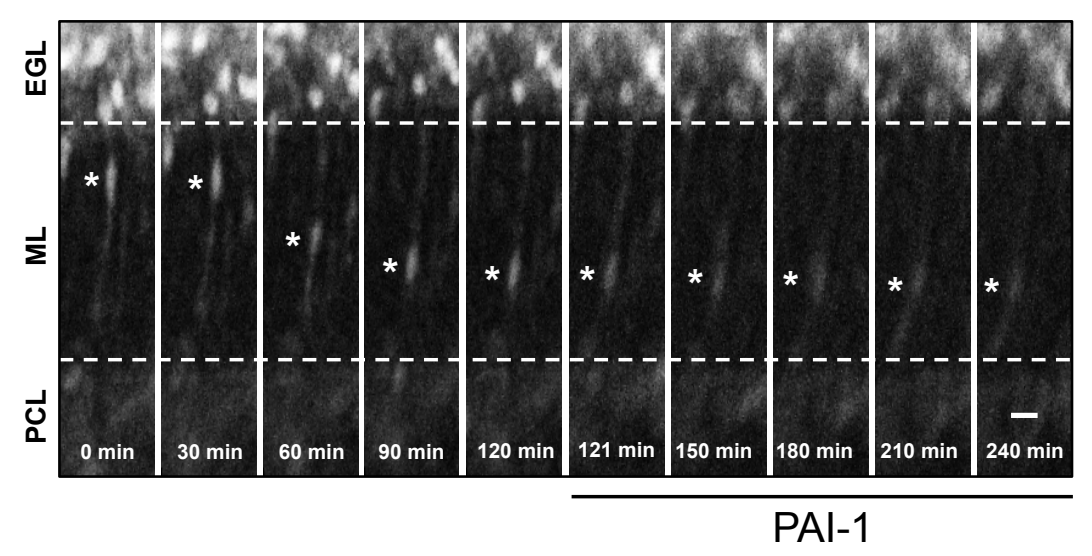

(d)

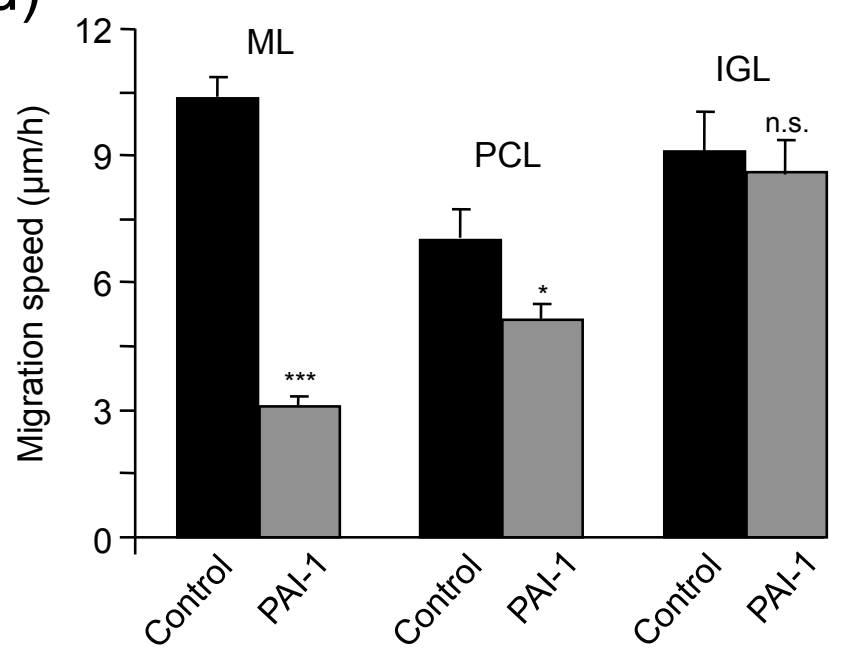

Fig. 5 
(a)

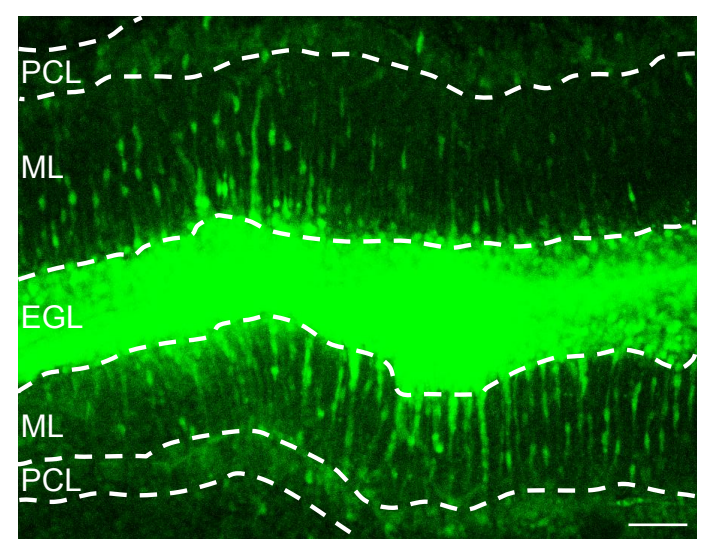

(c)

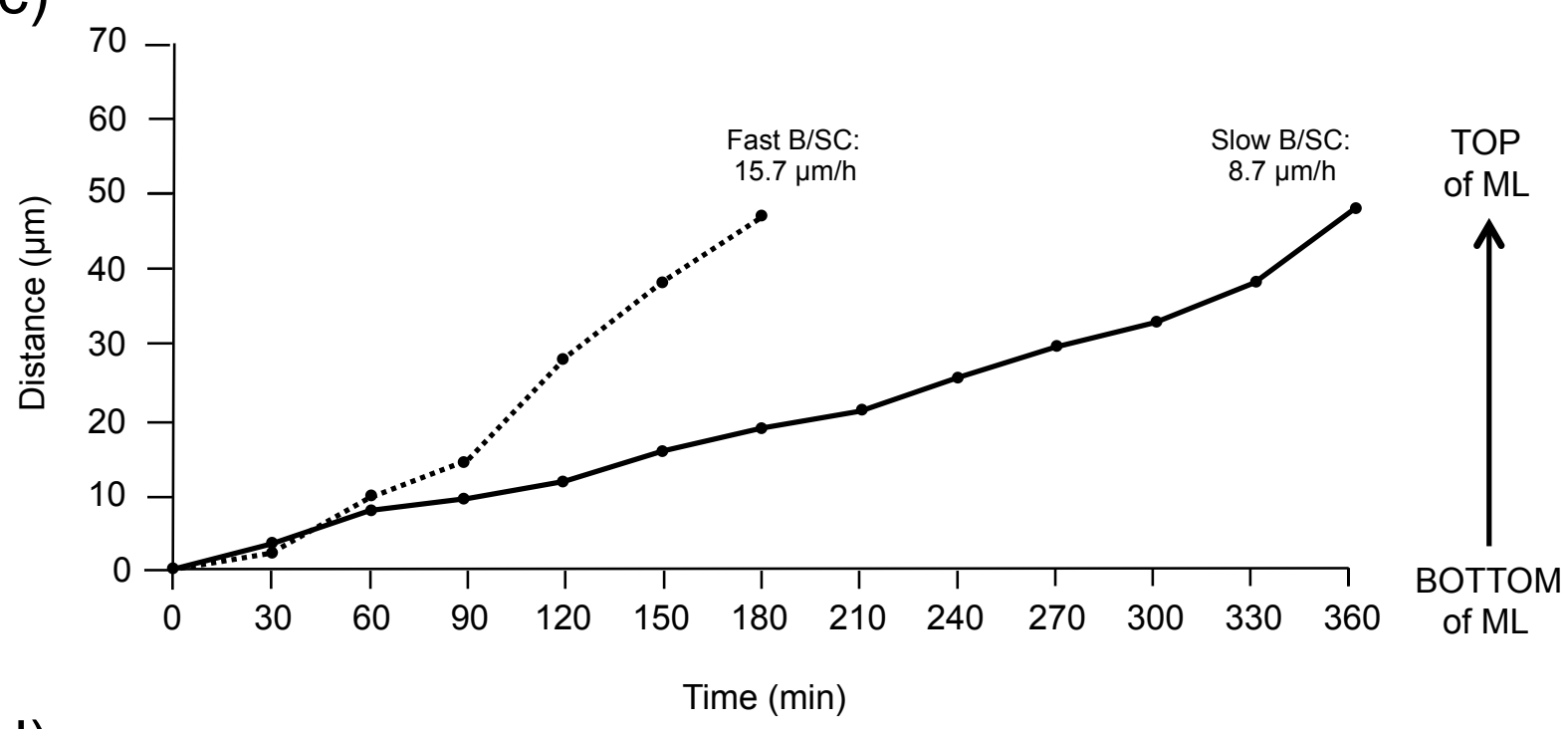

(d)

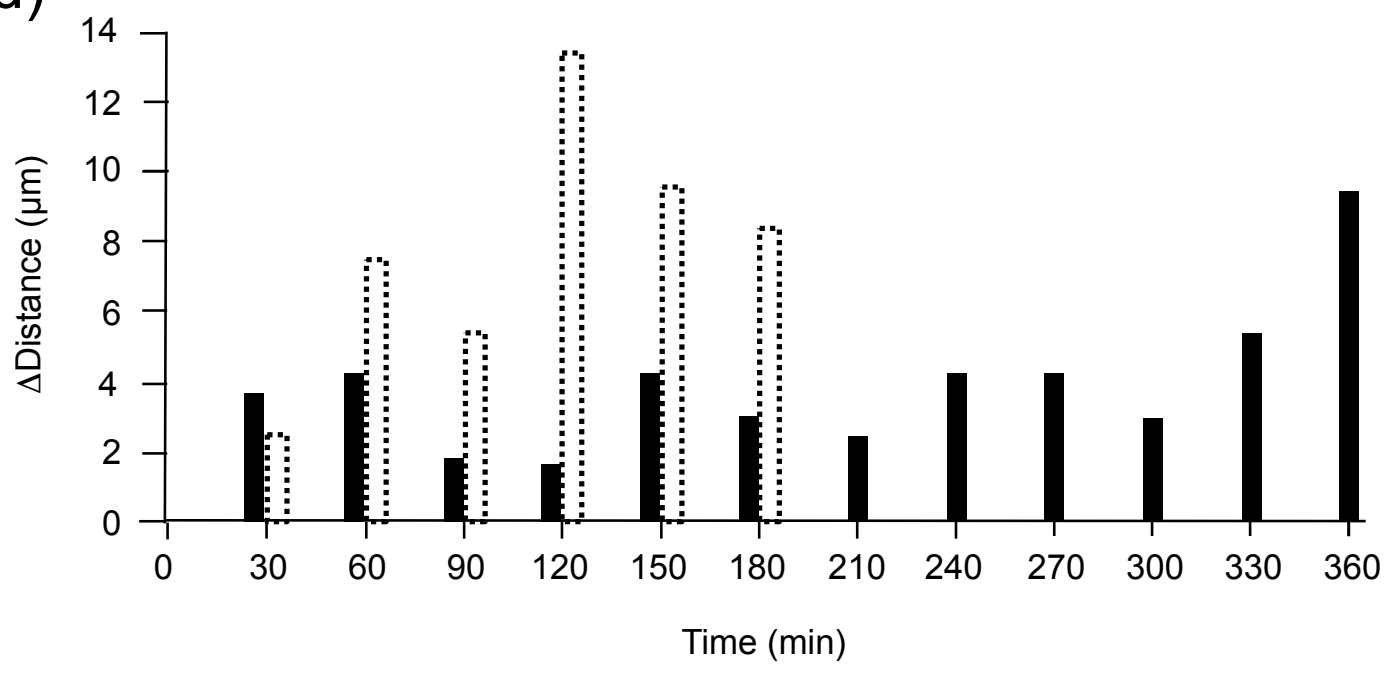

Fig. 6

Raoult et al. 
(a)

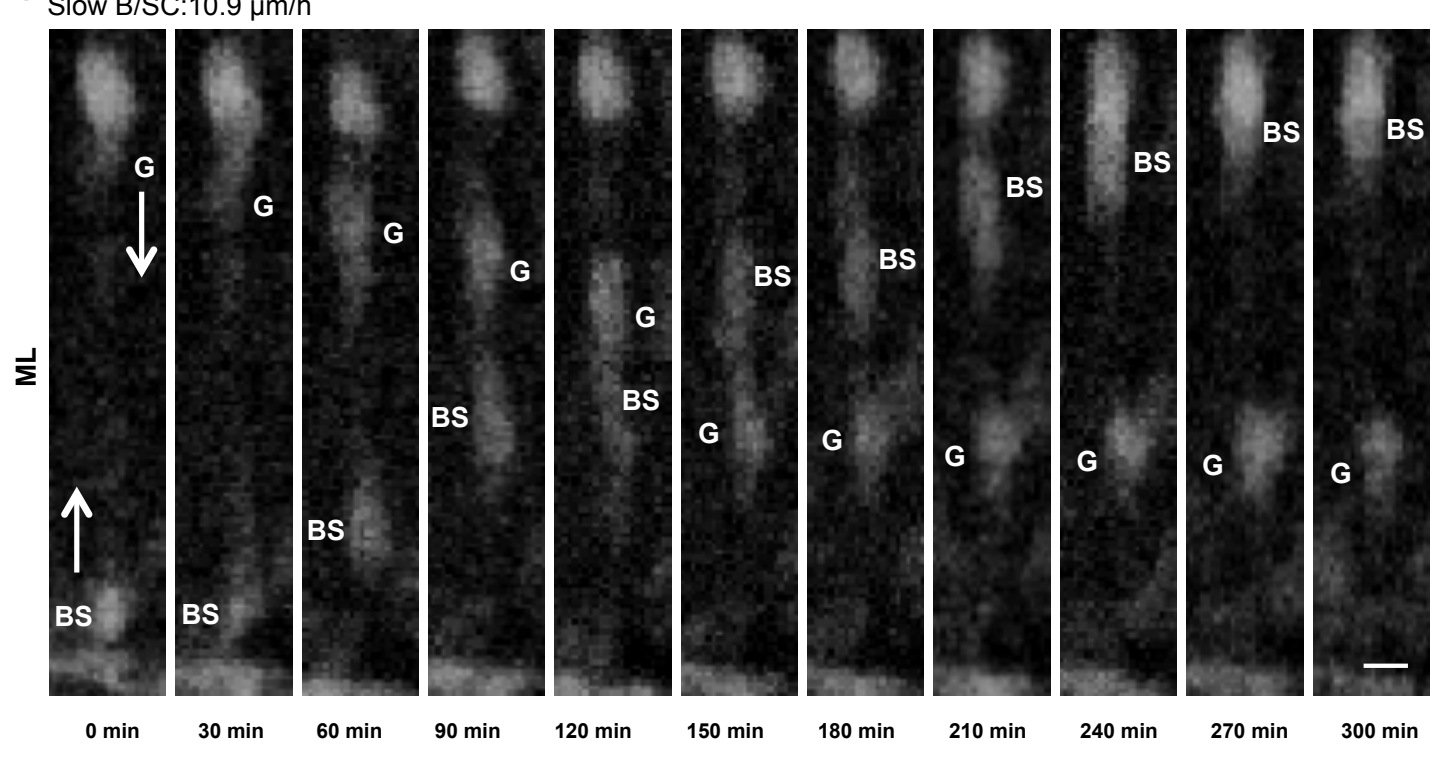

(b)

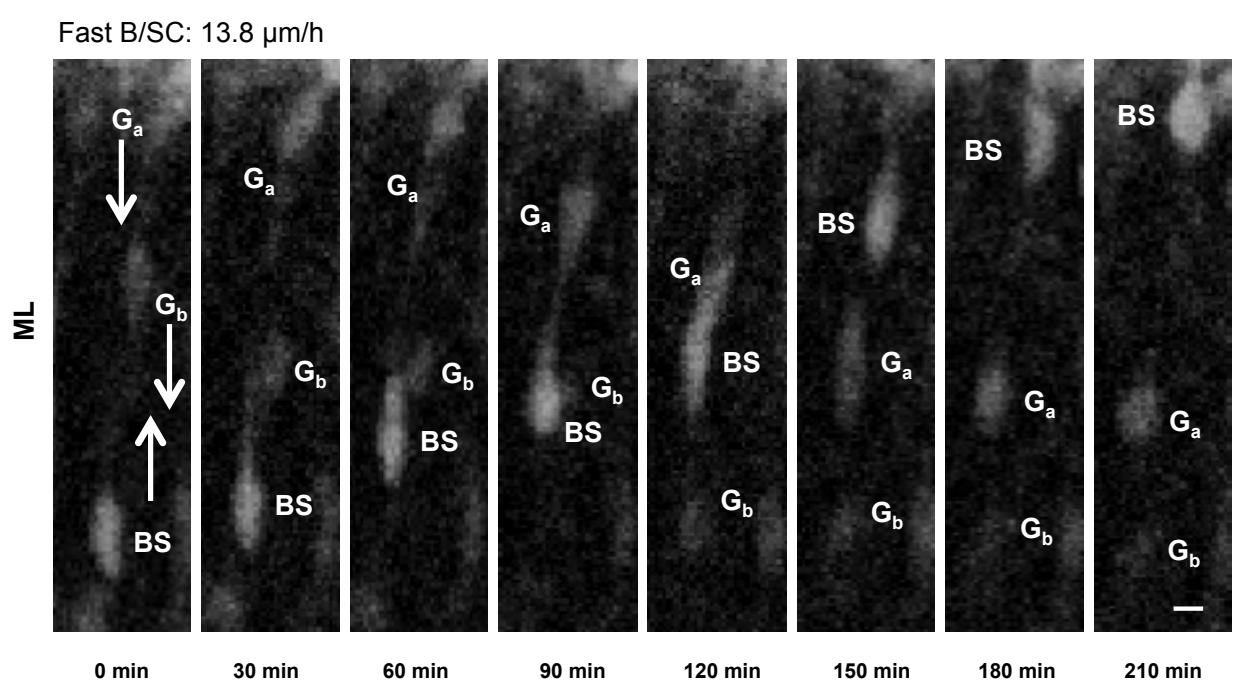

Fig. 7 
(a)

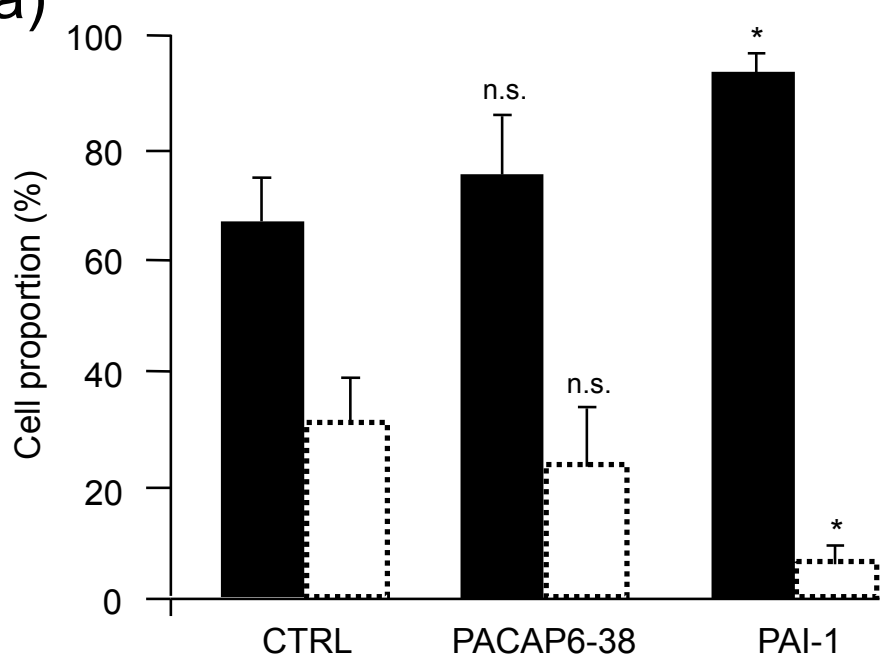

(b)

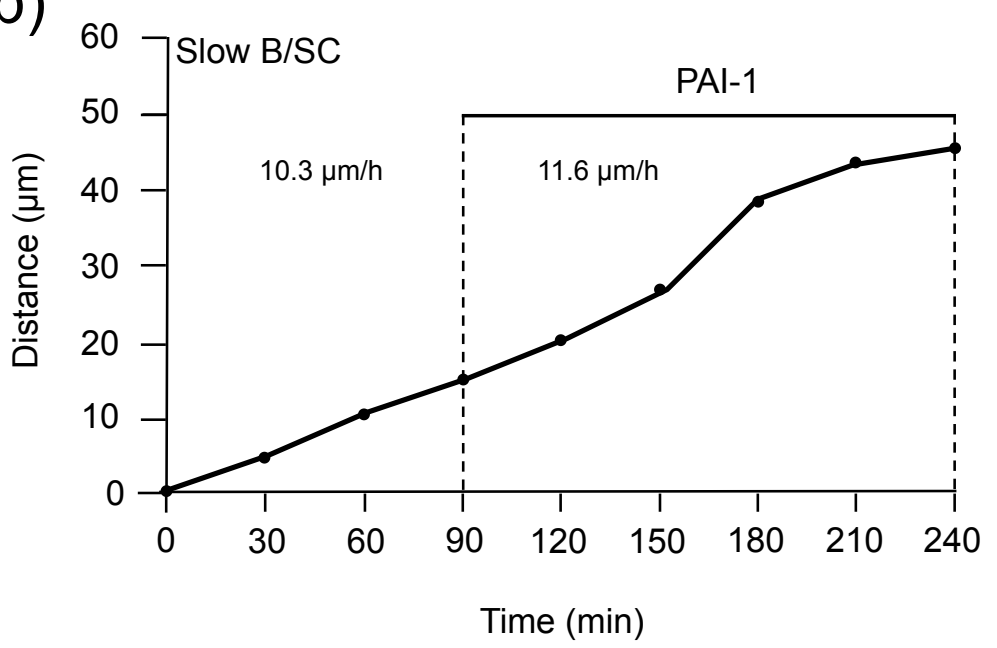

(c)

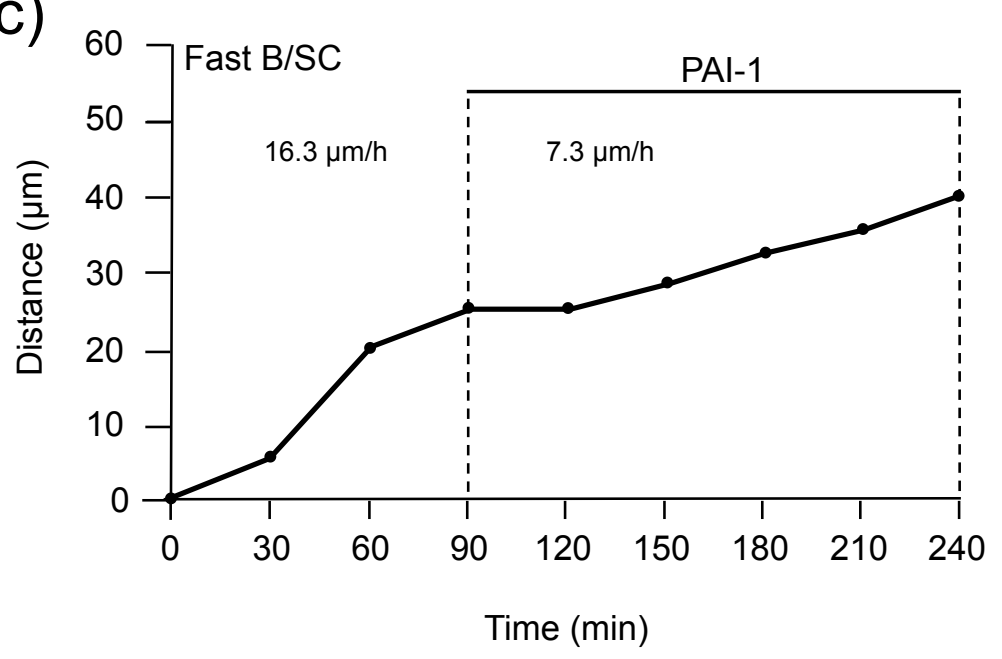

Fig. 8 